simple structure, low maintenance, gearless, full-scale power electronic converter interface, high power density and high inertia compared to any wind generator are the main advantages for PMSG [7].

Fuzzy controller, neural networks and model predictive controller are applied to machine-side converter (MSC) and grid-side converter (GSC) to obtain the optimal parameters which will make the performance of PMSG is better $[8,9]$. However, mention techniques are considered intelligent, but have some drawbacks like complex structure and their results have high oscillations [10]. Field-oriented control (FOC) has been preferred to apply to MSC to extract the optimal power from the wind [11]. GSC has been also controlled by voltage-oriented control (VOC) to stabilize the dc link voltage and controlling of real and reactive power injected to the grid. The two-level converter has been preferred to use because it is a simple structure and easy to control through space pulse width modulation (SPWM) $[12,13]$.

Grid faults affect power system reliability and PMSG output that is connected to the grid. FRT realization technique becomes more and more important which means PMSG must still be connected to the grid for a known time that has been determined according to electrical grid codes law. Consequently, only improved control techniques are not enough for FRT realization of PMSG under grid faults $[14,15]$. Hardware solutions have been used to assist PMSG to ride through grid faults. Proposed techniques are applied to enhance FRT capability like flexible alternating current transmission systems (FACTS), energy storage systems, superconducting magnetic energy storage, modified back-to-back converter and BC. The last type mentioned is preferred because of simplicity, low cost and easy control implementation $[16,17]$.

Nowadays optimization techniques are capable of tuning proportional integral (PI) controller at its optimal values to improve the dynamic performance of PMSG [18, 19]. PI controller is simpler, lower cost, high reliability for linear systems and easily implemented, but it suffers from poor performance during wind speed change or power from stator change. Thanks to optimization techniques like a new colony, particle swarm optimization (PSO) and whale optimization algorithm (WOA) are capable of tuning PI controller [19]. Nearly all papers concentrate on acquiring maximum power point tracking (MPPT) from PMSG by using optimization algorithms in recent years. This paper studies the impact of optimization techniques on FRT improvement and also compares three of optimization techniques to choose the best algorithm work with PMSG. Researchers also examine optimal values for crowbar resistance and its effect on PMSG actions. To limit the current, the $B C$ resistance value must be high and has a small value to limit the dc link voltage, so selecting the value has a great effect on the wind generator's dynamic behavior.

The main contribution of the paper can be concluded as:

- GWO, WOA and PSO have proposed techniques to solve the limitations for conventional PI.

- Dynamic system disturbance improved with GWO including $B C$ and enhanced FRT compared to other techniques

- A comparison is made between the conventional PI controller and proposed algorithms in case of normal and abnormal conditions

- The study depicts that the superior performance of the GWO compared to other techniques enhances the overall WECS efficiency and aids in FRT realization.

This paper is organized in the following sections: Sect. 2 presents the analysis of WEGS. Section 3 describes the modeling of MSC. Section 4 depicts the modeling of GSC. Section 5 illustrates FRT capability realization for PMSG with $B C$ and its control structure. Section 6 depicts the significance of meta-heuristic algorithms and their flowcharts. Section 7 presents a discussion of simulated results. Finally, the conclusion is summarized in Sect. 8.

\section{Analysis and modeling of WEGS}

The WEGS-based PMSG configuration is illustrated in Fig. 1. The wind power captured by the wind turbine is transmitted to PMSG. It is connected to voltage source converter (VSC), back-to-back converter and then to grid. The inputs parameters to the control system are $V_{\text {grid }} l_{\text {grid }}, V_{\mathrm{dc}}, V_{\text {wind }}$ $I_{\text {stator }} \beta$ and $\omega_{\mathrm{m}}$ to give the appropriate pulses to MSC and GSC according to these values. The parameters mentioned are grid voltage, grid current, dc link capacitor voltage, wind speed, pitch angle and mechanical speed.

\subsection{Modeling of variable-speed wind power}

Variable-speed wind turbine (VSWT) characteristics such as power coefficient $\left(C_{p}\right)$, tip speed ratio $(\lambda)$, mechanical power $\left(P_{\mathrm{m}}\right)$ and turbine torque $\left(T_{\text {tur }}\right)$ equations are expressed as surveys in $[4,20,21]$ :

$$
\begin{aligned}
& C_{\mathrm{p}}(\lambda, \beta)=0.5176\left(\frac{116}{\lambda_{i}}-0.4 \beta-5\right) \exp ^{-\frac{21}{\lambda_{i}}}+0.0068 \lambda \\
& \frac{1}{\lambda_{i}}=\frac{1}{\lambda+.08 \beta}-\frac{.035}{\beta^{3}+1}
\end{aligned}
$$




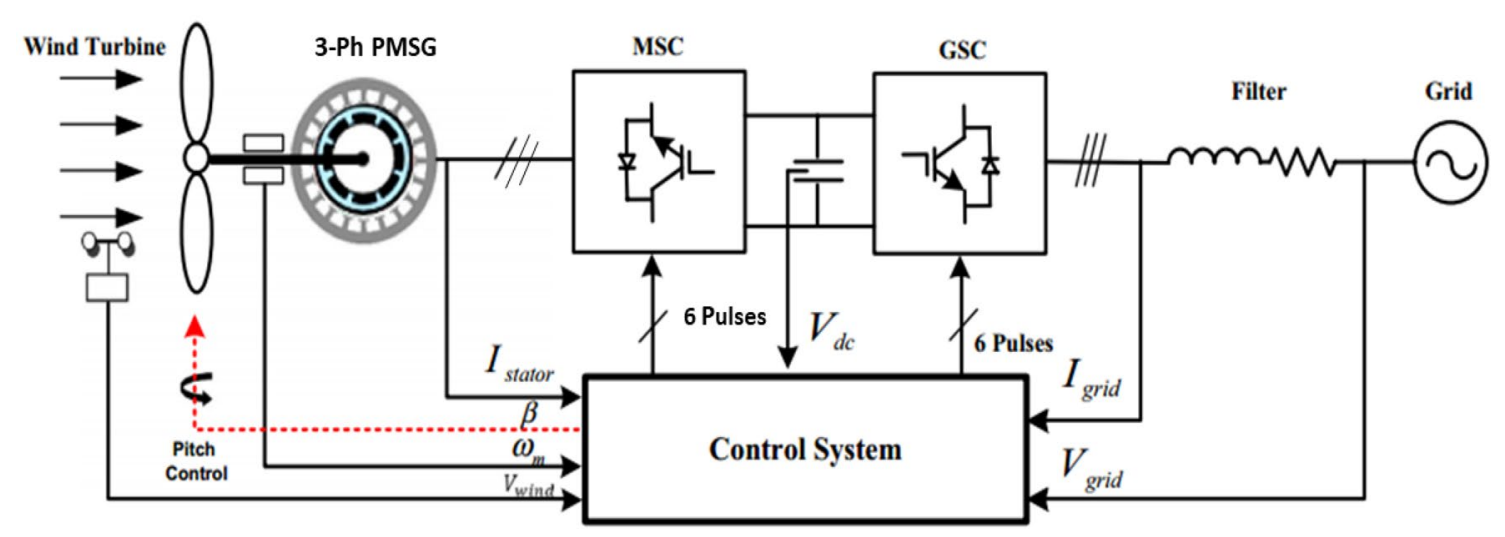

Fig. 1 Configuration of PMSG-based WEGS connected to the grid

$\lambda=\frac{\omega_{\mathrm{m}} * R}{V_{\text {wind }}}$

$p_{\mathrm{m}}=0.5 c_{\mathrm{p}} \rho A\left(V_{\text {wind }}\right)^{3}$

From Eq. (3), we can obtain the value of $\omega_{\mathrm{m}}$ at optimal $\lambda$ and operated wind speed:

$T_{\text {tur }}=\frac{P_{\mathrm{m}}}{\omega_{\mathrm{m}}}$

$T_{\text {tur }}=J_{\text {eq }} \frac{d \omega_{\mathrm{m}}}{d t}+B_{\text {eq }} \cdot \omega_{\mathrm{m}}+T_{\mathrm{e}}$

where $\rho$ is the air density, $A$ is the swept area of WT blades, $J_{\text {eq }}$ is the total equivalent inertia of turbine, $B_{\text {eq }}$ is the damping coefficient and $T_{\mathrm{e}}$ is the electromagnetic torque. An optimum value of $P_{m}$ is only gotten when the rate of change of $\frac{d p_{m}}{d_{\omega m}}$ is zero. To achieve that, Eq. (4) is used as follows:

$\frac{d p_{\mathrm{m}}}{d \omega_{\mathrm{m}}}=0.5 \rho A\left(V_{\text {wind }}\right)^{3} \cdot \frac{d C_{\mathrm{p}}(\lambda, \beta)}{d \omega_{\mathrm{m}}}$

The optimum value when $\beta$ equals zero, then the value of $C_{p}$ is dependent on $\lambda$ only.

The value of $\frac{d C_{p}}{d \omega_{m}}$ is shown as follows:

$\frac{d C_{\mathrm{p}}}{d \omega_{\mathrm{m}}}=\frac{d C_{\mathrm{p}}}{d \lambda_{i}} * \frac{d \lambda_{i}}{d \omega_{\mathrm{m}}}$

Then,

$$
\begin{aligned}
\frac{d p_{\mathrm{m}}}{d \omega_{\mathrm{m}}}= & 0.5 \rho A\left(V_{\text {wind }}\right)^{3} \cdot\left(\frac{1260}{\left(\lambda_{i}\right)^{3}}-\frac{114.39}{\left(\lambda_{i}\right)^{2}}\right)(e)^{(-21 / \lambda)} . \\
& \frac{V_{\text {wind }} * R}{\left(V_{\text {wind }}-0.035 R \omega_{\mathrm{m}}\right)^{2}}
\end{aligned}
$$

For obtaining the maximum power condition when $\left(V_{\text {wind }}-0.035 R \omega_{m}\right) \neq 0$ according to Eq. (9), $\lambda$ opt and $C_{p}$ opt values are 10.5 and 0.44 , respectively, at $\beta$ equal to zero and that is clear in the simulated results. The illustration of the optimal real power curve obtained under different wind speed values is depicted in [10].

\subsection{Modeling of a wind-driven PMSG}

The extended park transition from abc to dq is used for the investigation for the dynamic model of direct drive PMSG and the stator voltages $\mathrm{d}-\mathrm{q}$ components within the synchronous reference frame $[4,20,22]$.

$$
\begin{aligned}
& I_{\mathrm{ds}}=\frac{1}{s}\left(-V_{\mathrm{ds}}-R_{\mathrm{s}} I_{\mathrm{ds}}+\omega_{\mathrm{r}} L_{\mathrm{q}} I_{\mathrm{qs}}\right) / L_{\mathrm{d}} \\
& I_{\mathrm{qs}}=\frac{1}{s}\left(-V_{\mathrm{qs}}-R_{\mathrm{s}} I_{\mathrm{qs}}-\omega_{\mathrm{r}} L_{\mathrm{d}} I_{\mathrm{ds}}\right) / L_{\mathrm{q}}
\end{aligned}
$$

$\left(V_{\mathrm{ds}}\right)^{*}=-R_{\mathrm{s}} I_{\mathrm{ds}}-L_{\mathrm{s}} \frac{d}{d t} I_{\mathrm{ds}}+L_{\mathrm{s}} \omega_{\mathrm{e}} I_{\mathrm{qs}}$

$\left(V_{\mathrm{qs}}\right)^{*}=-R_{\mathrm{s}} I_{\mathrm{qs}}-L_{\mathrm{s}} \frac{d}{d t} I_{\mathrm{qs}}-L_{\mathrm{s}} \omega_{\mathrm{e}} I_{\mathrm{qs}}$

$\omega_{\mathrm{e}}=\omega_{\mathrm{m}} \cdot P$

$T_{\mathrm{e}}=\frac{3 p}{2}\left(\lambda_{\mathrm{r}} I_{\mathrm{qs}}-\left(L_{\mathrm{d}}-L_{\mathrm{q}}\right) I_{\mathrm{ds}} I_{\mathrm{qs}}\right)$ 
For surface-mounted (non-salient) $L_{d}=L_{\mathrm{q}}$

$T_{\mathrm{e}}=\frac{3 p}{2}\left(\lambda_{\mathrm{r}} I_{\mathrm{qs}}\right)$

where $\left(V_{\mathrm{ds}}, V_{\mathrm{qs}}\right), R_{\mathrm{s}^{\prime}}, \lambda_{\mathrm{r}^{\prime}} T_{\mathrm{m}^{\prime}}\left(I_{\mathrm{ds} \prime^{\prime}} I_{\mathrm{qs}}\right), \omega_{\mathrm{r}^{\prime}} p, T_{\mathrm{e}^{\prime}} L_{\mathrm{s}}$ and $\omega_{\mathrm{e}}$ are $d-q$ axis stator voltages, stator resistance, rotor flux linkage, mechanical torque, $d$ - $q$ axis stator currents, rotor mechanical speed, number of poles, electromagnetic torque, stator inductance and electrical angular rotor speed $(\mathrm{rad} / \mathrm{s})$, respectively.

\section{MSC modeling and analysis}

MSC has been mainly applied for controlling the rotor speed of wind generators to maximize output power. Direct current in MSC is set to be equal to zero in order to reduce the current flow for a known torque and also eliminate the resistive losses. The GWO, WOA and PSO techniques were applied to MSC to select the optimum values for the controller. The MPPT uses TSR to achieve Te optimal value based on the equations discussed in Sect. 2.1. The quadrature current can be calculated as per Eq. 16 . Equations (17), (18) are used for implementation d-q stator voltage components of MSC $[9,10,13]$. The park has been transformed from $d_{\mathrm{q}}$ to $a b c$ to get $V^{*} a, V^{*} b$ and $V^{*} c$; then, the SPWM takes the decision for switching states. The block diagrams of vector control for MSC-based GWO, WOA and PSO are depicted in Figs. 2, 3 and 4, respectively.

$$
\begin{aligned}
& \left(V_{\mathrm{sd}}\right)^{*}=V_{\mathrm{d}}^{\prime}-\left(V_{\mathrm{d}}\right)^{\mathrm{comp}}=L_{\mathrm{d}} l_{\mathrm{d}}-L_{\mathrm{q}} \omega_{\mathrm{e}} l_{\mathrm{q}} \\
& \left(V_{\mathrm{sq}}\right)^{*}=V_{\mathrm{d}}^{\prime}-\left(V_{\mathrm{q}}\right)^{\mathrm{comp}}=L_{\mathrm{q}} l_{\mathrm{q}}+\omega_{\mathrm{e}} \omega_{\mathrm{pm}}
\end{aligned}
$$

\section{GSC modeling and analysis}

The GSC is used to inject the real power into the grid at the unity power factor and to keep the dc link voltage at prescribed limits where $V_{\mathrm{dc}}=1150 \mathrm{~V}$ using VOC. The VOC is combined from the outer control loop which is used to regulate the dc link voltage to its reference value and the inner control loop which is used to supply the grid with zero reactive power. The $\mathrm{d}-\mathrm{q}$ axis voltage components of the GSC are $[9,10]$.

$\left(V_{\mathrm{gd}}\right)^{*}=V_{\mathrm{id}}-R_{\mathrm{g}} I_{\mathrm{gd}}-L_{\mathrm{g}} \frac{d}{d t} I_{\mathrm{gd}}-L_{\mathrm{g}} \omega_{\mathrm{e}} I_{\mathrm{gq}}$

$\left(V_{\mathrm{gq}}\right)^{*}=V_{\mathrm{iq}}-R_{\mathrm{g}} l_{\mathrm{gq}}-L_{\mathrm{g}} \frac{d}{d t} l_{\mathrm{gq}}-L_{\mathrm{g}} \omega_{\mathrm{e}} I_{\mathrm{gq}}$

where $R_{g^{\prime}} L_{g^{\prime}}, V_{\text {id }}$ and $V_{\text {iq }}$ are the grid resistance, grid inductance and the two inverter voltage components, respectively. Injection active power $\left(P_{\mathrm{g}}\right)$ and reactive power $\left(Q_{\mathrm{g}}\right)$ from PMSG to the grid can be obtained as follows:

$P_{\mathrm{g}}=1.5 V_{\mathrm{gd}} l_{\mathrm{gd}}$

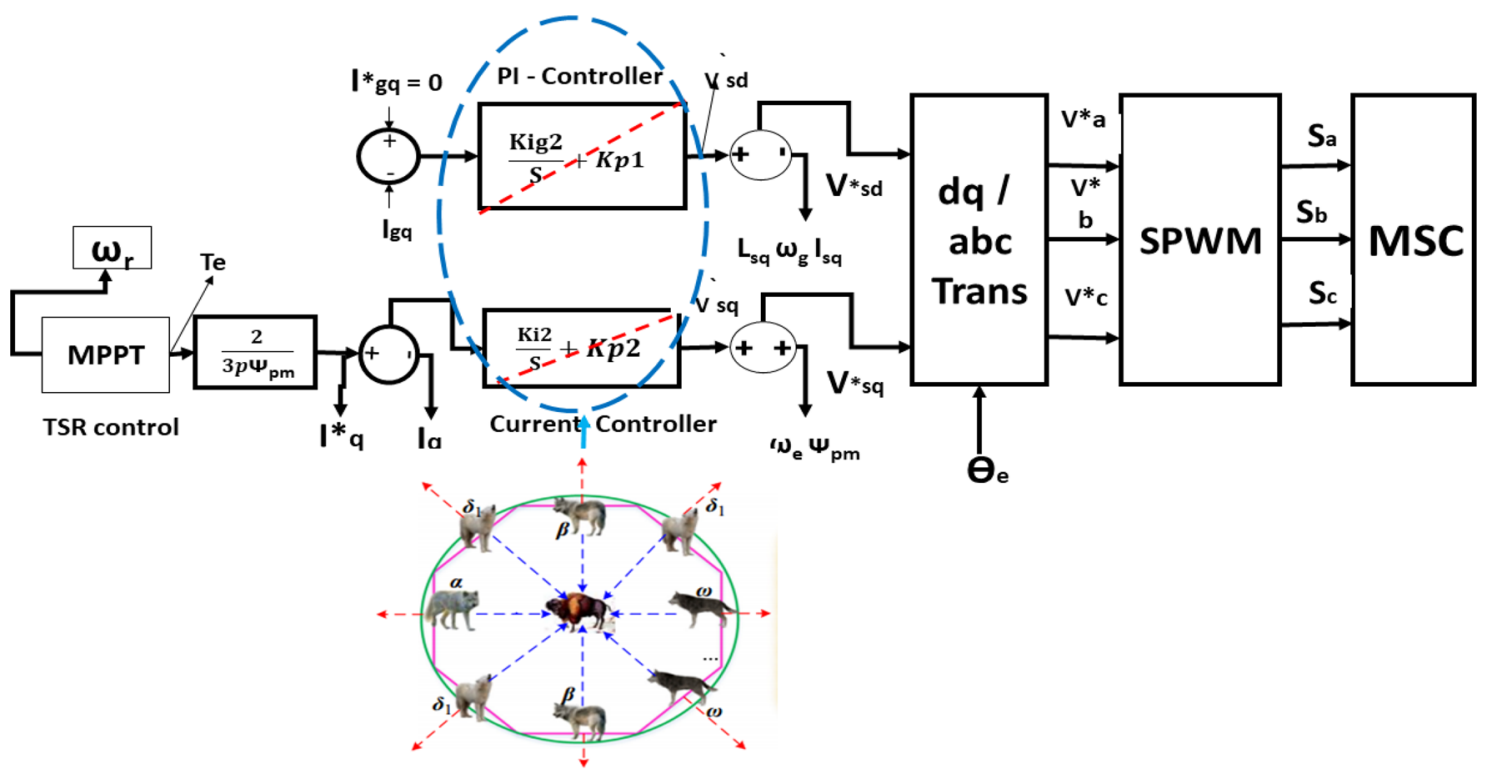

Fig. 2 Vector control structure for MSC-based GWO 


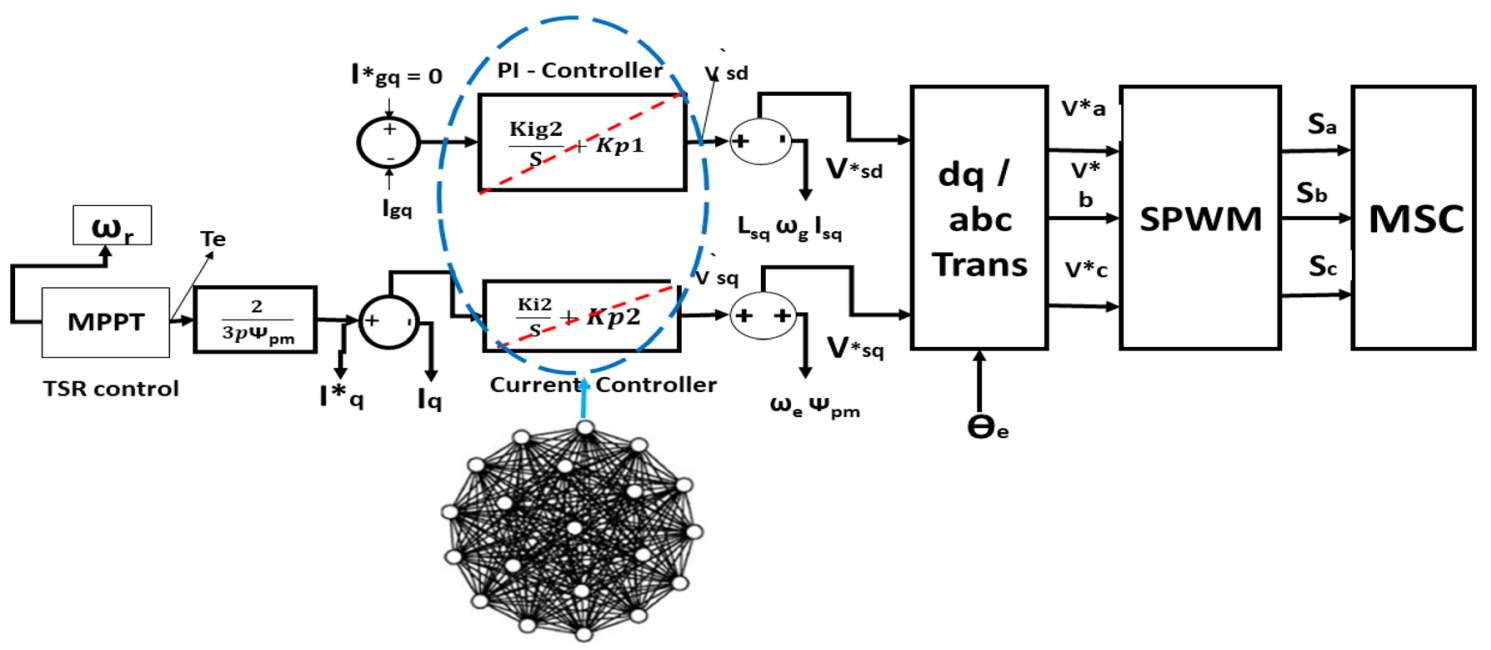

Fig. 3 Vector control structure for MSC-based PSO

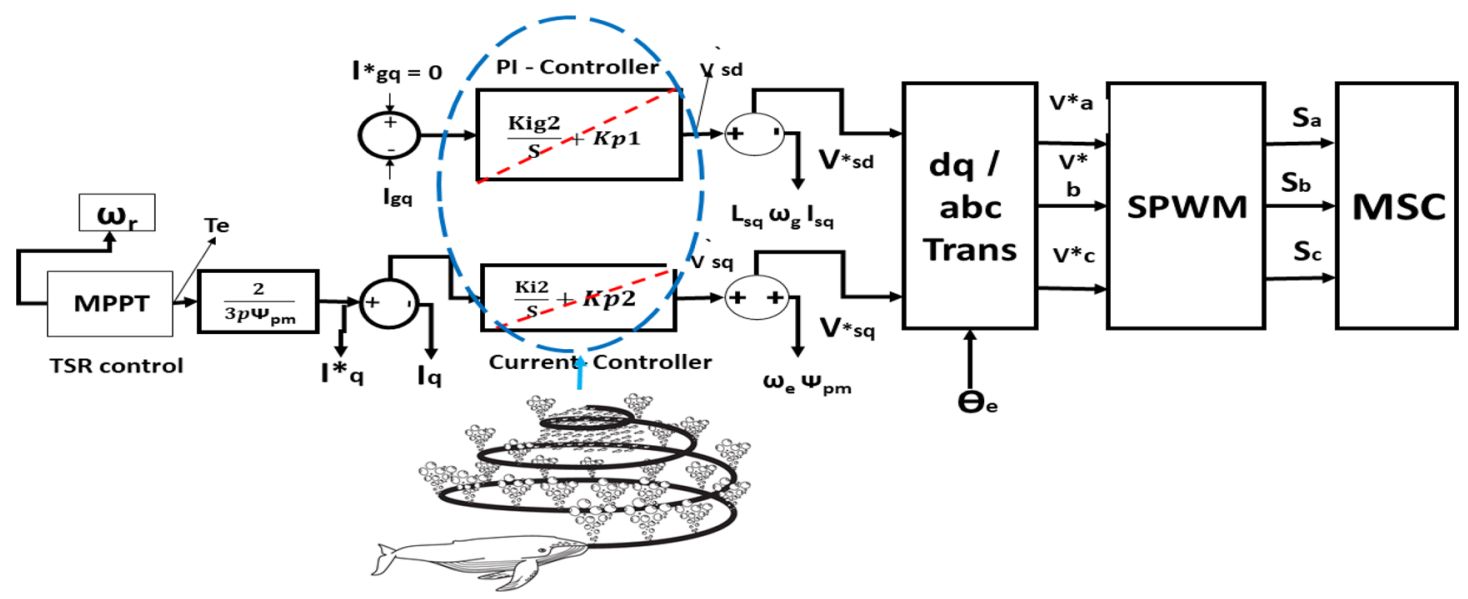

Fig. 4 Vector control structure for MSC-based WOA

$Q_{\mathrm{g}}=1.5 \mathrm{~V}_{\mathrm{gd}} \mathrm{I}_{\mathrm{gq}}$

From Eqs. (21), (22) controlling of $P_{g}$ and $Q_{g}$ can be done by varying $I_{\mathrm{d}}$ and $l_{\mathrm{q}}$ currents, respectively. In order to inject the total of active power generated from the wind turbine, dc voltage must be constant according to Eq. (23). Dc link voltage can be determined from relation $V_{\mathrm{dc}} \geq 1.633 v_{\mathrm{g}}$ [13].

$c \cdot \frac{d V_{\mathrm{dc}}}{d t}=\frac{P_{\mathrm{t}}}{V_{\mathrm{dc}}}-\frac{P_{\mathrm{g}}}{V_{\mathrm{dc}}}$

where $C$ is the capacitance of the dc link capacitor and $P_{t}$ is the active power from the wind turbine. Figure 5 illustrates the block diagram of vector control of GSC (Fig. 6).

\section{FRT capability realization for PMSG with BC}

For new grid codes, wind-driven PMSG is needed to enhance grid transient stability and reliability with FRT capability. PMSG must stay connected to the grid during short-term voltage dip and inject reactive power after fault clearance. Previous studies were sure that improved controller methods are not enough for FRT. BC has been chosen as a hardware solution because of the low cost and control structure simplicity as illustrated in Fig. 7 [15]. BC system is proposed to be inserted in dc link to dissipate the active power during the grid faults [14]. It combined from a high-rated-power resistor with a series switch as depicted in Fig. 6 . The duty ratio $\left(D_{S W}\right)$ for the $B C$ switch 


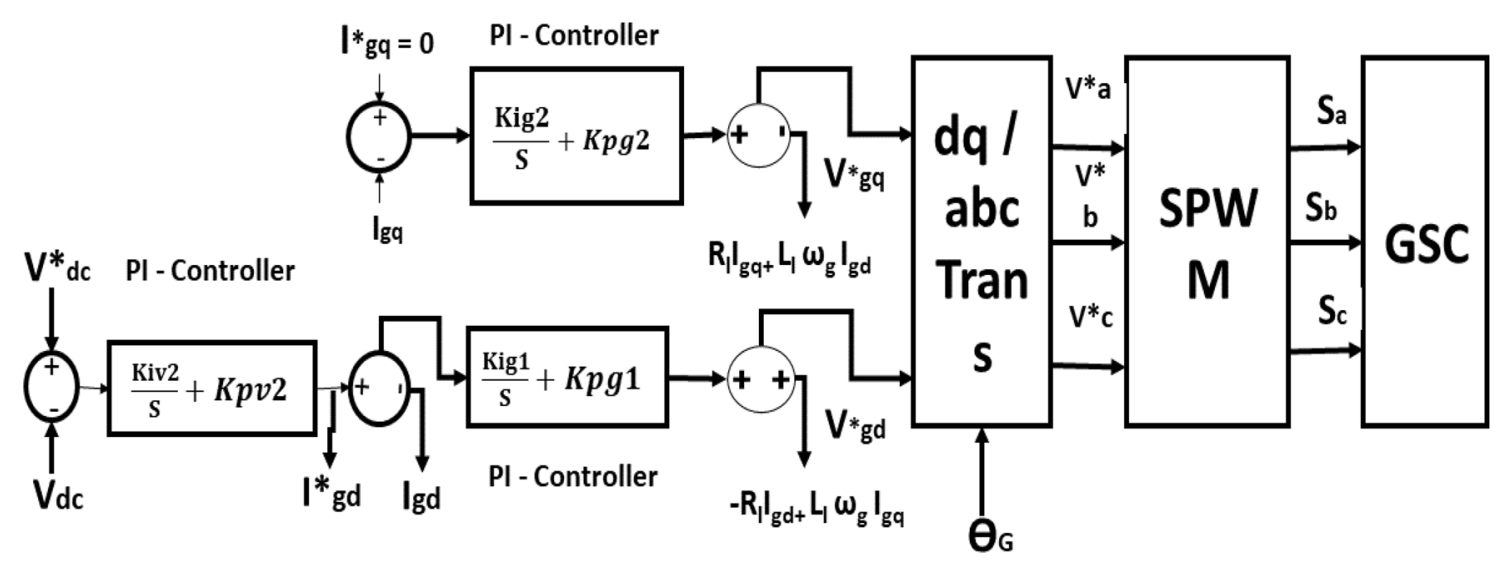

Fig. 5 Vector control structure for the grid-side PWM converter

Fig. 6 Connection of BC at dc link

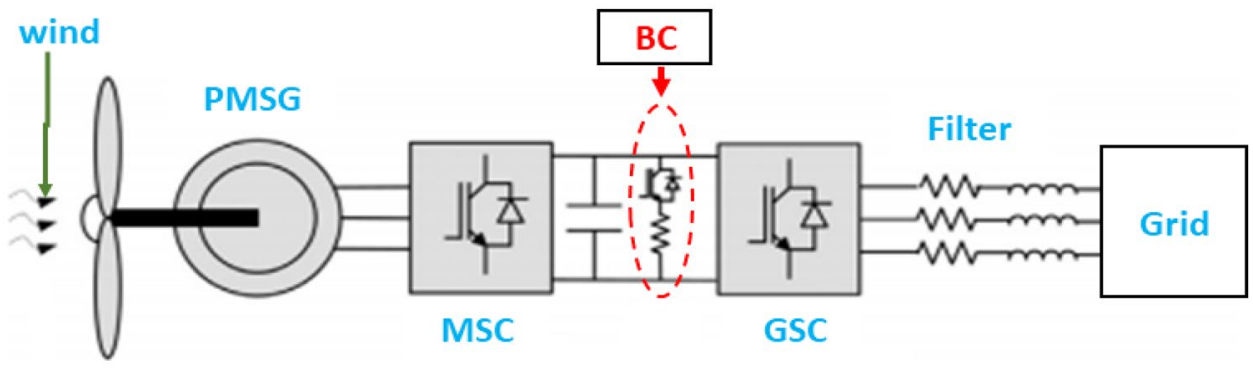

Fig. 7 BC controller block diagram (a)

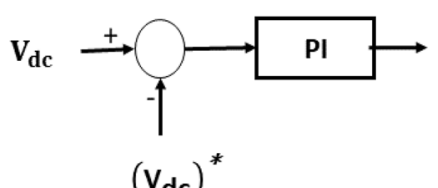

(b)

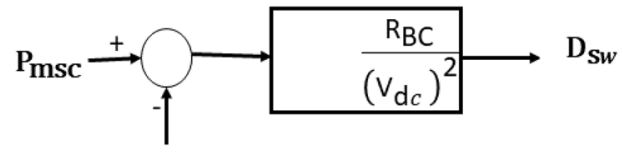

Pgsc (c)

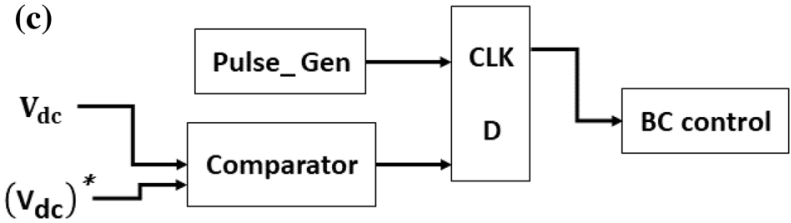

depends on the difference between generator power from MSC and the grid power from GSC [23]. At normal grid operation, $P_{\mathrm{BC}}$ equal to zero and under abnormal grid operation PBC does not equal zero because of a mismatch that occurs between $P_{\mathrm{MSC}}$ and $P_{\mathrm{GSC}}$.

Which is expressed as:

$P_{\mathrm{BC}}=P_{\mathrm{MSC}}-P_{\mathrm{GSC}}$

$D_{\mathrm{SW}}=\frac{R_{\mathrm{BC}}}{\left(V_{\mathrm{dc}}\right)^{2}} P_{\mathrm{BC}}$ where $P_{\mathrm{BC}}$ is the power dissipated by $\mathrm{BC}$ and where $\mathrm{RBC}$ is the braking resistance. $\mathrm{BC}$ can dissipate surplus power to protect the dc link from overvoltage that may destroy the dc link. Thanks to power electronic voltage source converter (VSC) that have the capability of reactive power injection after fault clearance to support voltage. In this paper, the two tasks have been performed by VSC and BC including optimization techniques, meaning FRT capability realization to improve the dynamic performance of PMSG [14]. 


\section{Meta-heuristic algorithms}

There are many statistical and conventional techniques like Taguchi technique, response surface method (RSM) [24], artificial neural network (ANN) [12, 25] and affine projection algorithm (APA) [14] where are applied for fine-tuning the $\mathrm{PI}$ controller employed in the regulatory system for different power system components. But, these techniques depend on the initial values, so meta-heuristic algorithms such as PSO [26], cuckoo search algorithm (CSA) [27], WOA, Bee algorithm [28], gravitational search algorithm (GSO) [29] and differential evolution algorithm are competitive solutions for fine-tuning the parameters of PI controllers. Figure 8 illustrates the steps needed to find the best solution and the three proposed techniques

\subsection{GWO applied on MSC}

GWO is a meta-heuristic algorithm introduced by Mirjalili et al. [26, 29], which represents the local manner of gray wolves. A group of them contains 5-12 wolves roughly. The group has a leader named alpha $(\alpha)$, supported by secondary wolves named beta $(\beta)$, which aid $a$ in decisionmaking. The rest members of the group are named $\delta$ and $\omega$ as shown. GWO was applied to the PI controller for a wind-driven PMSG to identify the optimal parameter gains for improving FRT capability and MPPT. The control costs as follows:

Minimize $F(x)=\int_{0}^{T} W_{1}\left|i_{d}-i_{d}^{*}\right|+W_{2}\left|\omega_{m}-\omega_{m}^{*}\right|+W_{3}\left|Q_{s}-Q_{s}^{*}\right|+W_{4}\left|V_{d c}-V_{d c}^{*}\right|$

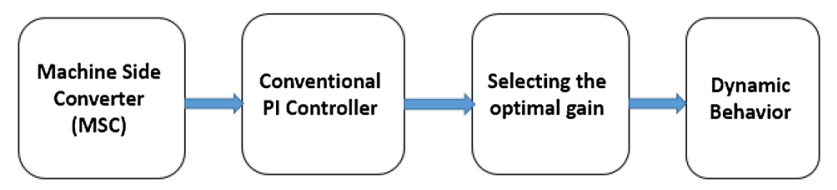

Fig. 8 Four steps to finding the perfect solution
PI control parameters are required to be tuned optimally which are denoted as $K_{p}$ and $K_{i}$, where the number of iterations $=100$, agents' number $=6$ and $T$ is the total operating time. The weights $w_{1}, w_{2}, w_{3}$ and $w 4$ are used to scale the magnitude of control costs which are identically

Fig. 9 Flowchart for technique proposed by GWO

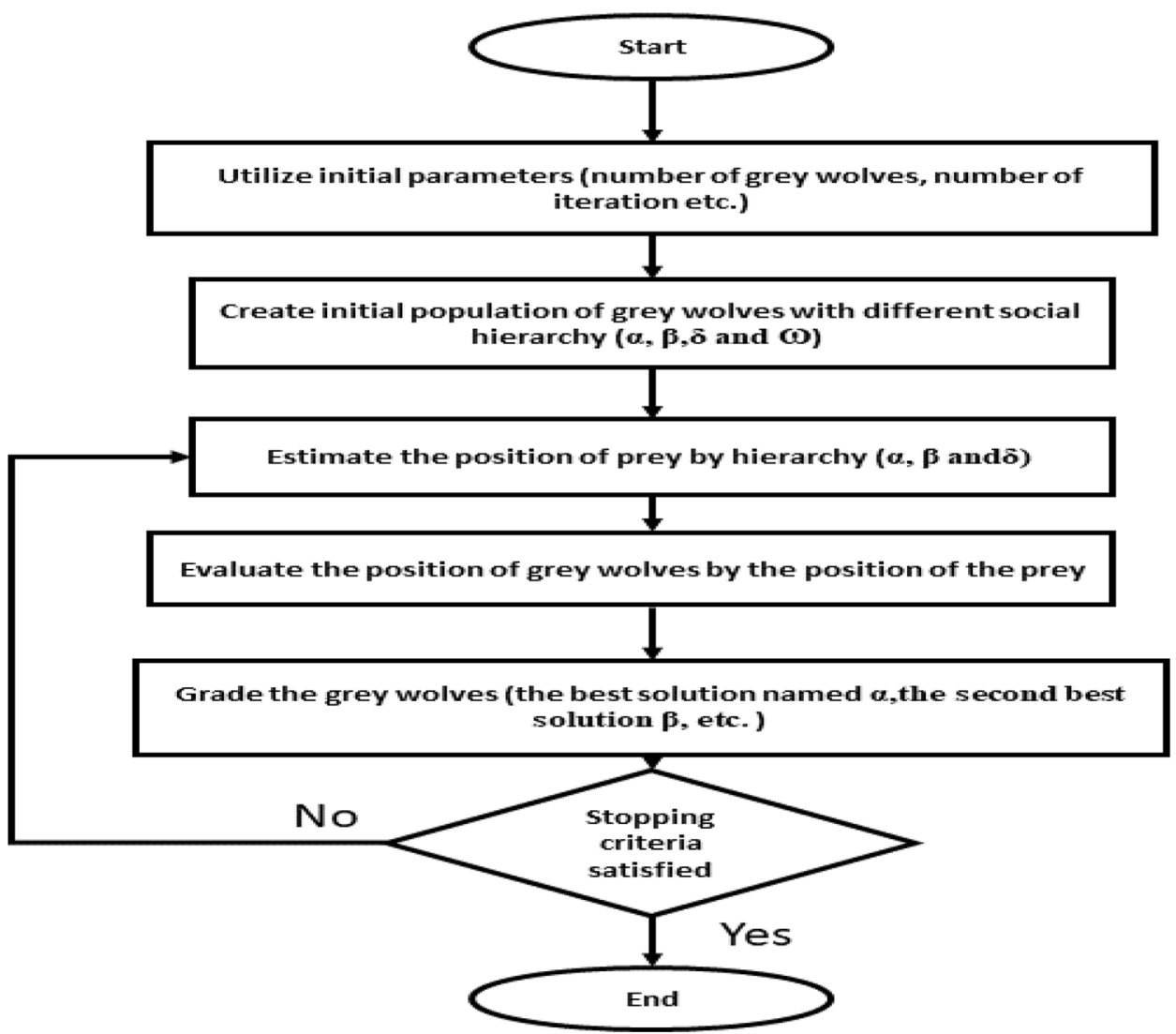


Fig. 10 Flowchart for the GWO technique suggested

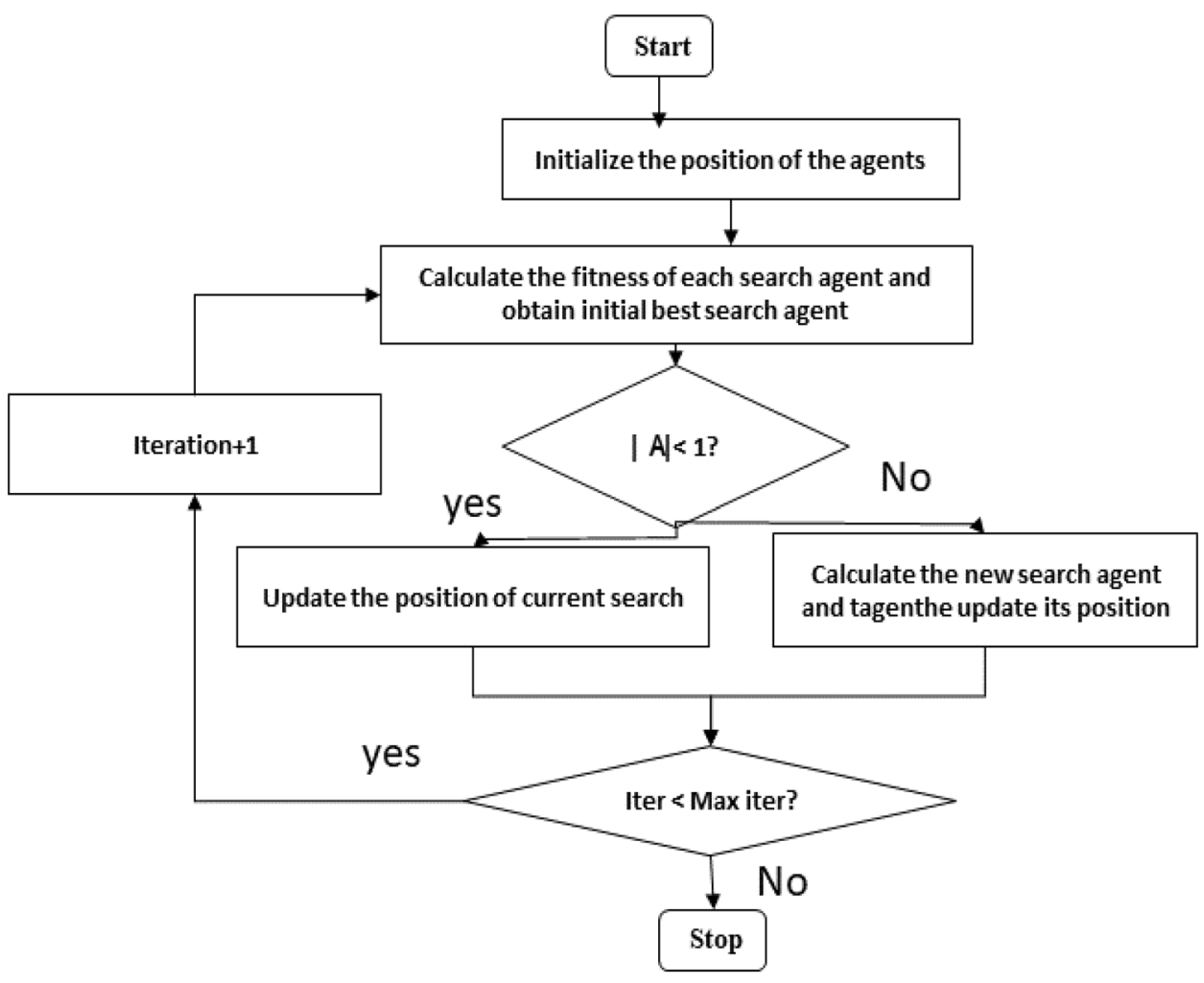

chosen to be $4 \times 10^{5}$ for all. The GWO algorithm flowchart is depicted in Fig. 9.

\subsection{WOA applied on MSC}

The WOA is one of the novel meta-heuristic techniques. It introduces the same manner of GWO in finding the optimal gain factors for PI. It also used for enhancing MPPT and FRT capability. The WOA algorithm flowchart as illustrated in Fig. 10.

\subsection{PSO used for MSC}

The PSO, motivated by bird running social behavior, is a stochastic optimization technique based on population. The main objective of applying PSO to MSC is to get the optimal gains for the PI controller. It has also been used to improve the MPPT and FRT capabilities. The PSO algorithm flowchart is illustrated in Fig. 11. Table 1 shows the optimal gain factors for the PI controller where GWO, PSO and WOA are applied to MSC. Table 2 depicts the PI controllers applied on GSC where are not changed according to [10, $23,30]$.

\section{Analysis of simulated results and discussion}

Case 1 A comparative study among PSO and conventional PI controller in case of multi-step change of wind speed

Initially, the application of a three-step change in wind speed at different times which are $5 \mathrm{~s}, 10 \mathrm{~s}$ and $15 \mathrm{~s}$, respectively, depicts the impact of PSO on the dynamic performance of PMSG. Steady-state error and overshoot are much better for PSO compared to conventional PI. The values for $T_{\mathrm{e}}, I_{\mathrm{q}}-\mathrm{MSC}, \omega_{\mathrm{r}}$ and $P_{\mathrm{s}}$ values are affected by wind speed variations due to the aforementioned equations for modeling of PMSG. Values for $Q_{s}$ and $I_{\mathrm{d}}-\mathrm{MSC}$ are equal to zero due to unity power factor (UPF) operation. The $V_{\mathrm{dc}}$ is maintained at a constant rated value because of 
Fig. 11 Flowchart for PSO technique proposed

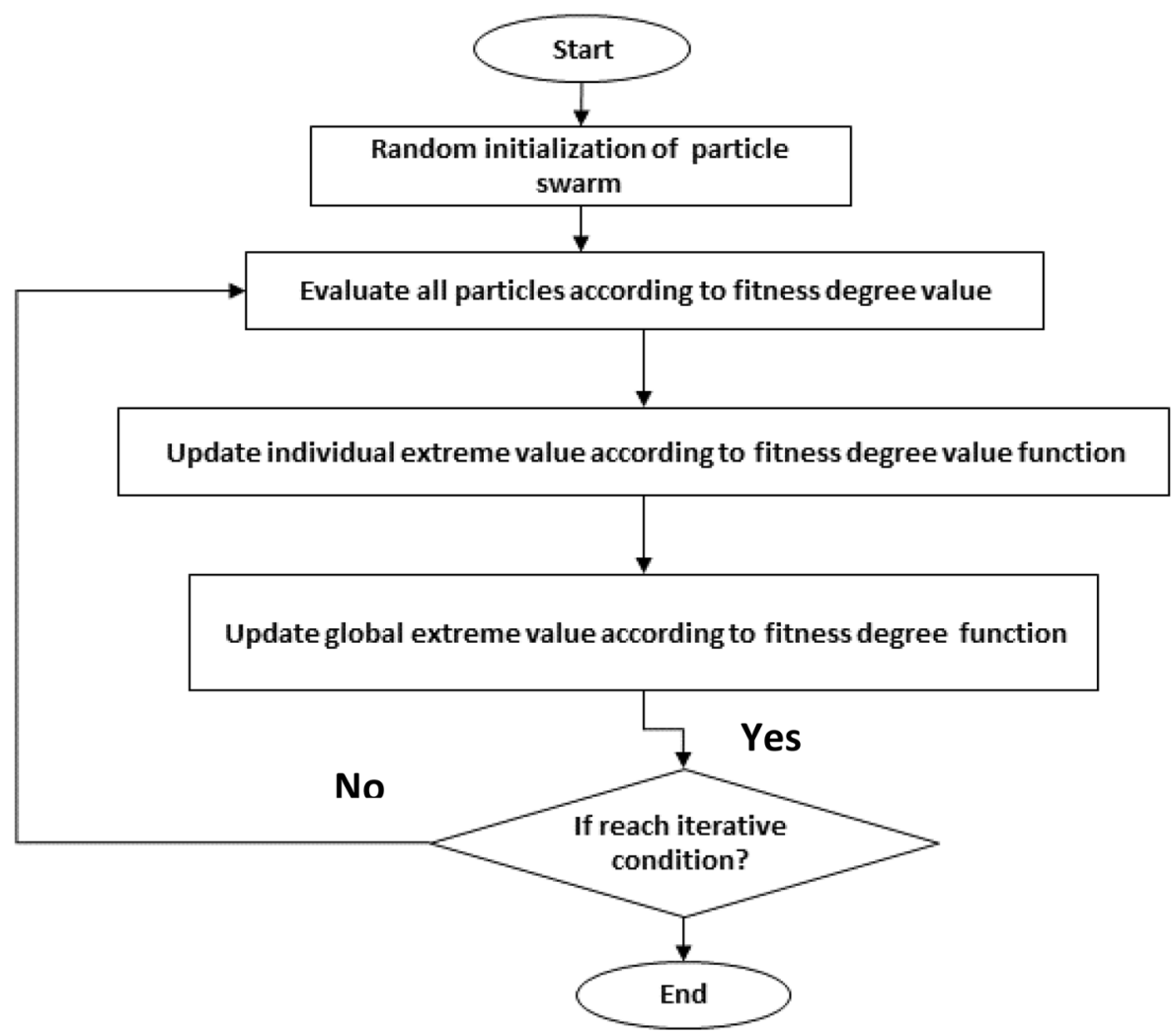

the controller of GSC that indicates that the power transferred from MSC to GSC (Fig. 12).

\begin{tabular}{lllll}
\hline Technique & $K_{p 1}$ & $K_{p 2}$ & \multicolumn{1}{l}{$K_{i 1}$} & \multicolumn{1}{l}{$K_{i 2}$} \\
\hline Ref [10] & 1.4 & 1.4 & 136.11 & 136.11 \\
GWO & 2.902 & 2.902 & 199.2117 & 199.2117 \\
WOA & 2.993 & 2.993 & 199.3436 & 199.3436 \\
PSO & 3 & 300 & 1.1395 & 117.7865 \\
\hline
\end{tabular}

Table 2 Gain factors for PI on GSC

\begin{tabular}{lllllll}
\hline Technique & $K_{p 3}$ & $K_{p 4}$ & $K_{p 5}$ & $K_{i 3}$ & $K_{i 4}$ & $K_{i 5}$ \\
\hline Ref [10] & 8 & 400 & 0.83 & 5 & 0.83 & 5 \\
GWO & 8 & 400 & 0.83 & 5 & 0.83 & 5 \\
WOA & 8 & 400 & 0.83 & 5 & 0.83 & 5 \\
PSO & 8 & 400 & 0.83 & 5 & 0.83 & 5 \\
\hline
\end{tabular}


Fig. 12 Simulated results a wind speed profile, $\mathbf{b}$ power coefficient $\left(C_{\mathrm{p}}\right)$, c injected active power $\left(P_{\mathrm{s}}\right)$ to the grid, $\mathbf{d}$ injected reactive power $\left(Q_{\mathrm{s}}\right)$ to the grid, e $\omega_{\mathrm{r}}$ f rotor speed $\left(\omega_{\mathrm{r}}\right)$, g direct current for MSC $\left(I_{\mathrm{d}}-\right.$ MSC), $\mathbf{h}$ quadrature current for $\left(I_{\mathrm{q}}-\mathrm{MSC}\right)$, i dc link voltage $\left(V_{\mathrm{dc}}\right)$

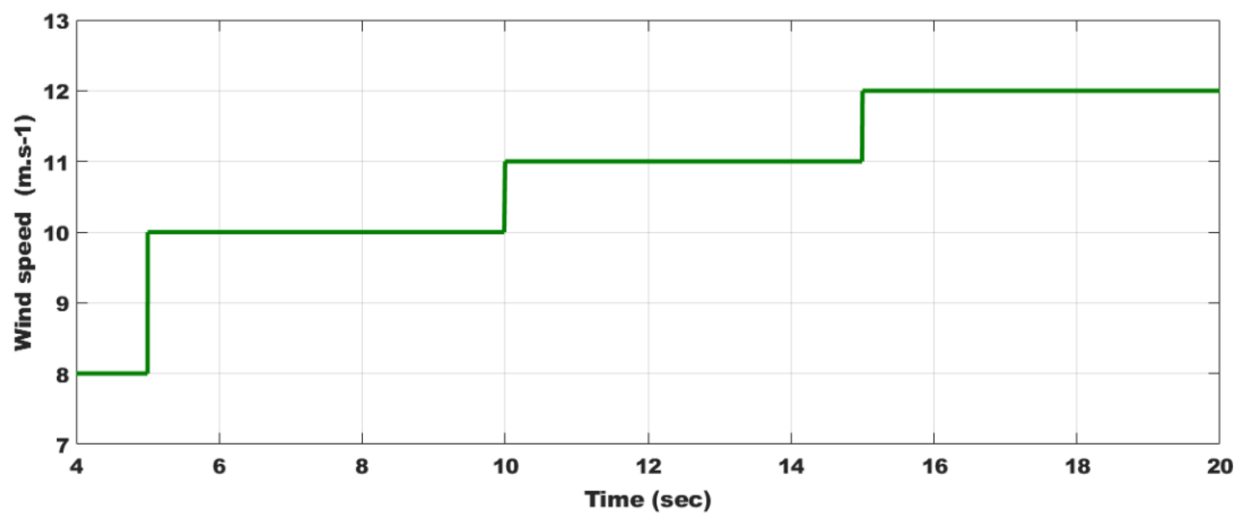

(a)

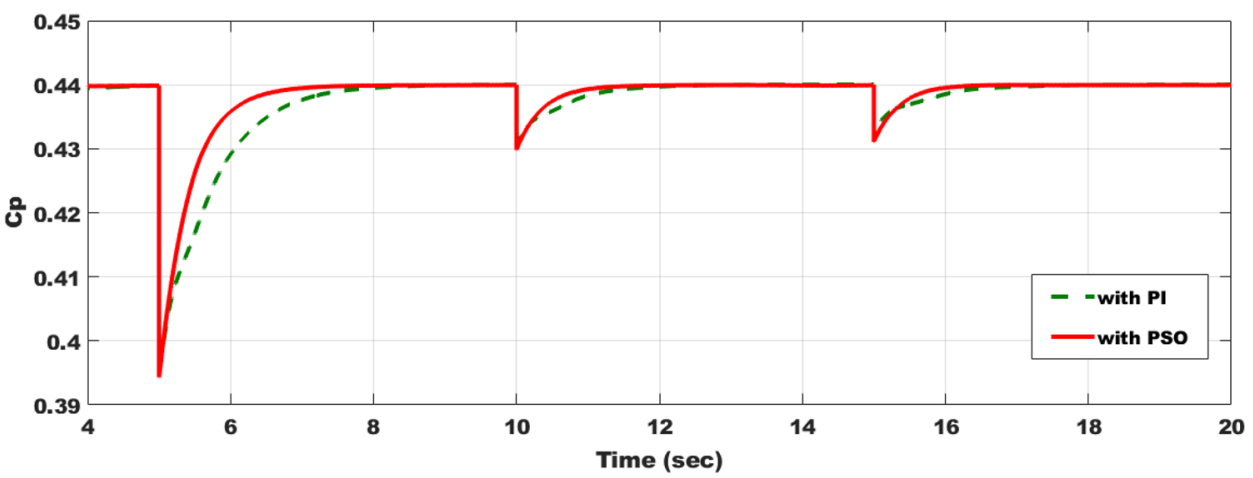

(b)

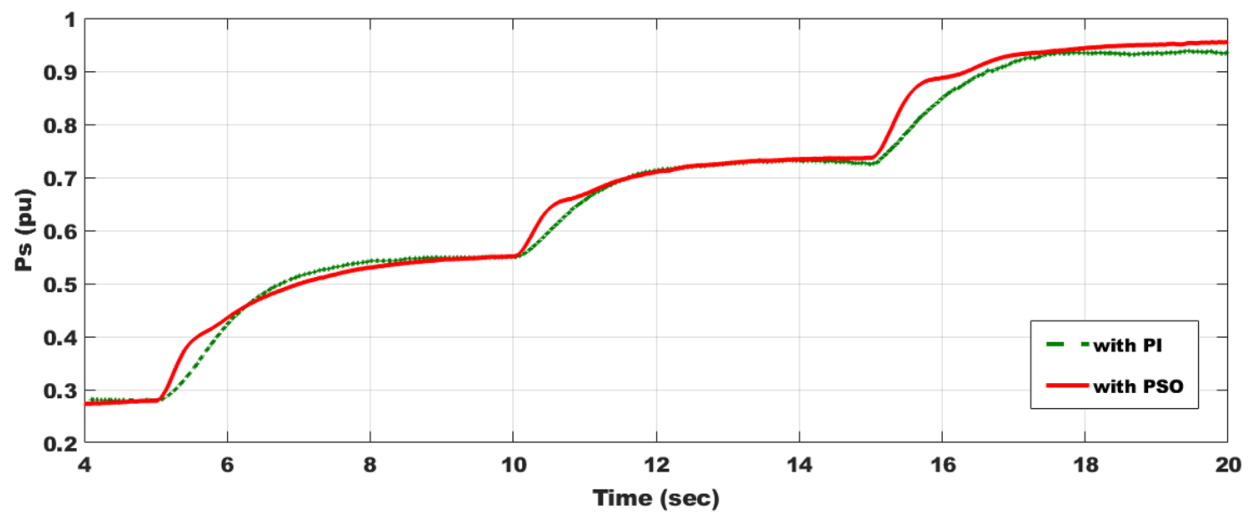

(c) 
Fig. 12 (continued)

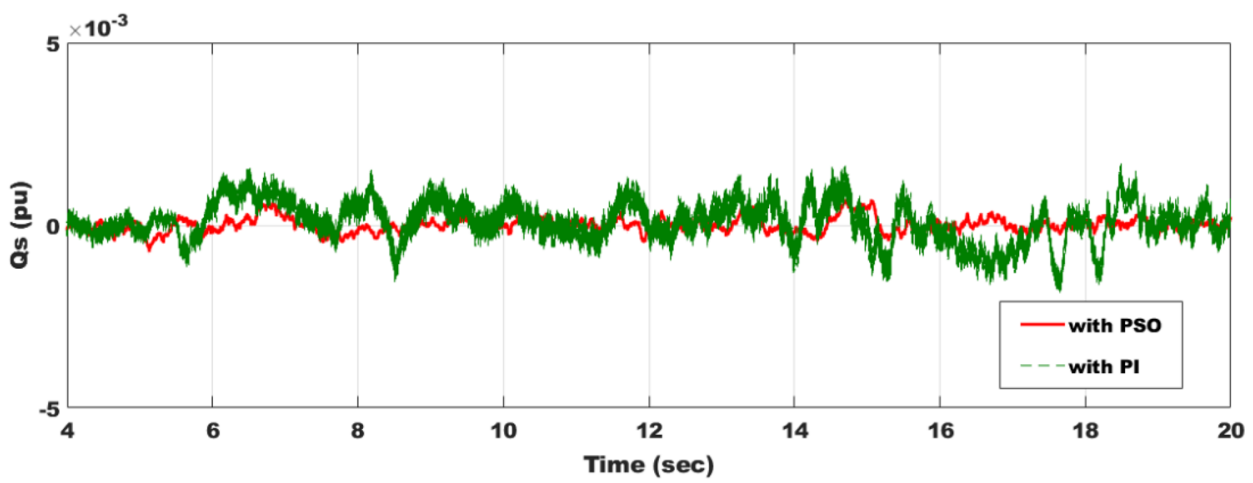

(d)

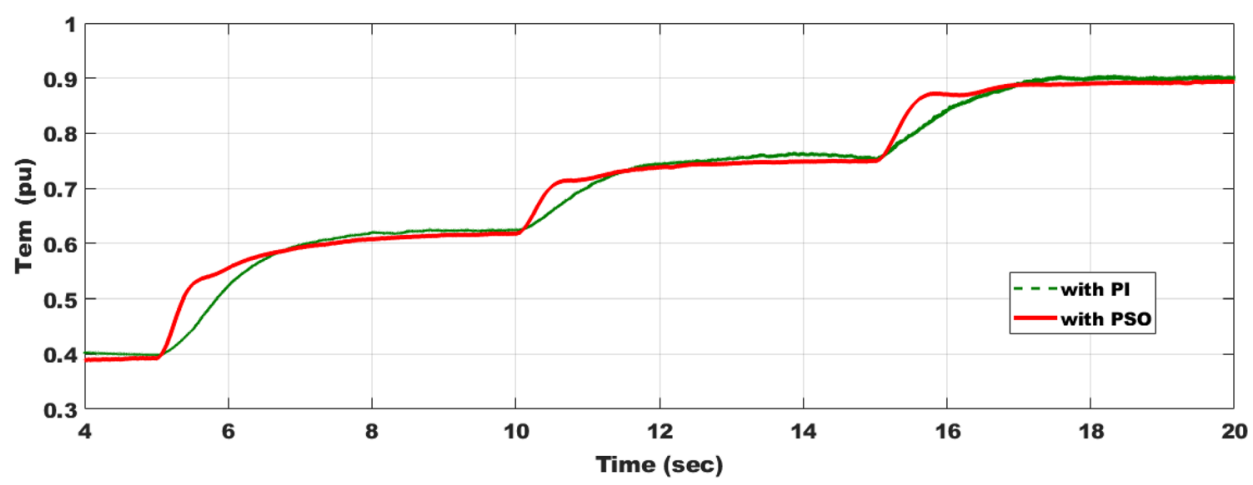

(e)

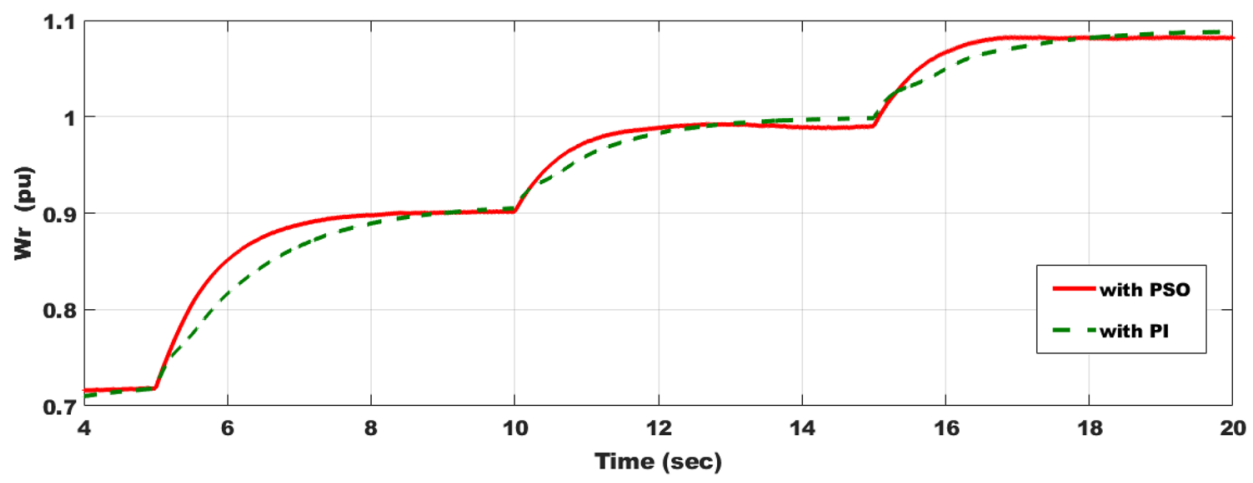

(f) 
Fig. 12 (continued)

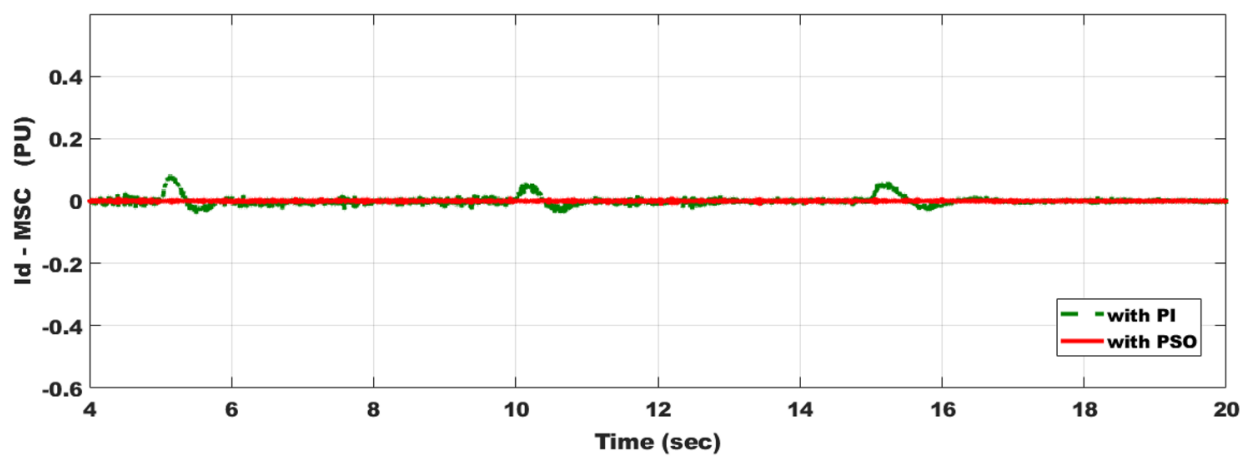

(g)

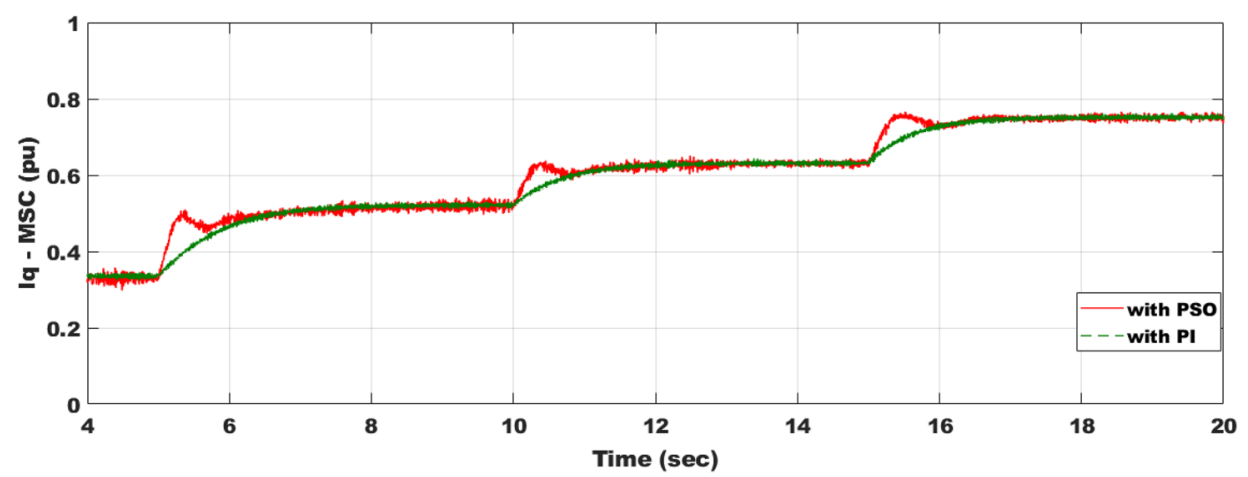

(h)

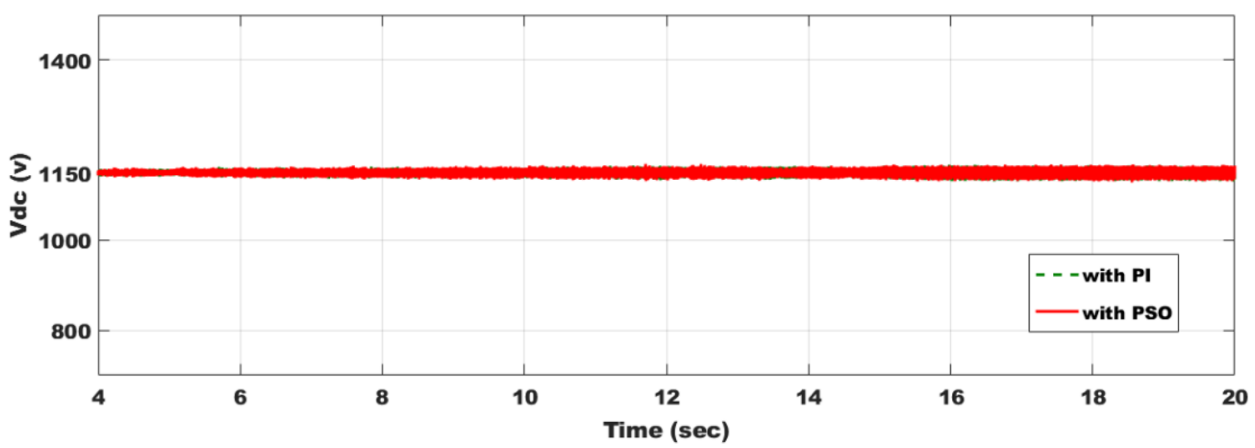

(i)

Case 2 Comparison between PSO, WOA and GWO under a three-step wind speed change

Simulated results show that GWO and WOA are superior compared to PSO, but WOA and GWO seem to be identically. Overshoot and steady-state errors are improved as compared to PSO with GWO and WOA. Under the optimal power coefficient and optimal tip speed ratio, the proposed optimization techniques were successful in operating PMSG (Fig. 13). 
Fig. 13 Simulated results a injected $P_{\mathrm{s}}$ to the grid, $\mathbf{b}$ injected $Q_{s}$ to the grid, c rotor speed $\left(\omega_{\mathrm{r}}\right)$, d electromagnetic torque $\left(T_{\mathrm{e}}\right)$, e direct current for MSC $\left(I_{\mathrm{d}}-\mathrm{MSC}\right)$, f dc link voltage $\left(V_{\mathrm{dc}}\right), \mathbf{g}$ tip speed ratio, $\mathbf{h}$ power coefficient $\left(C_{p}\right)$

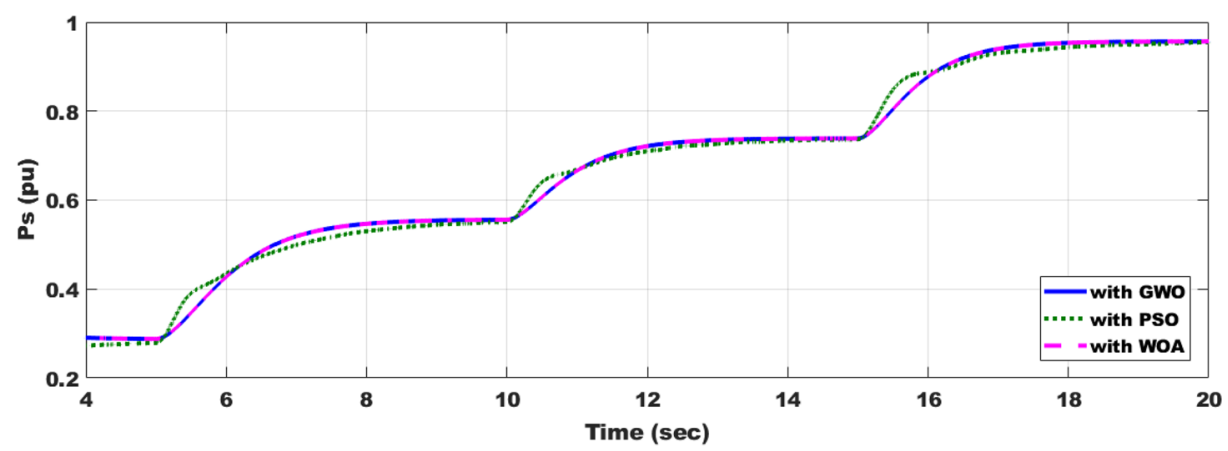

(a)

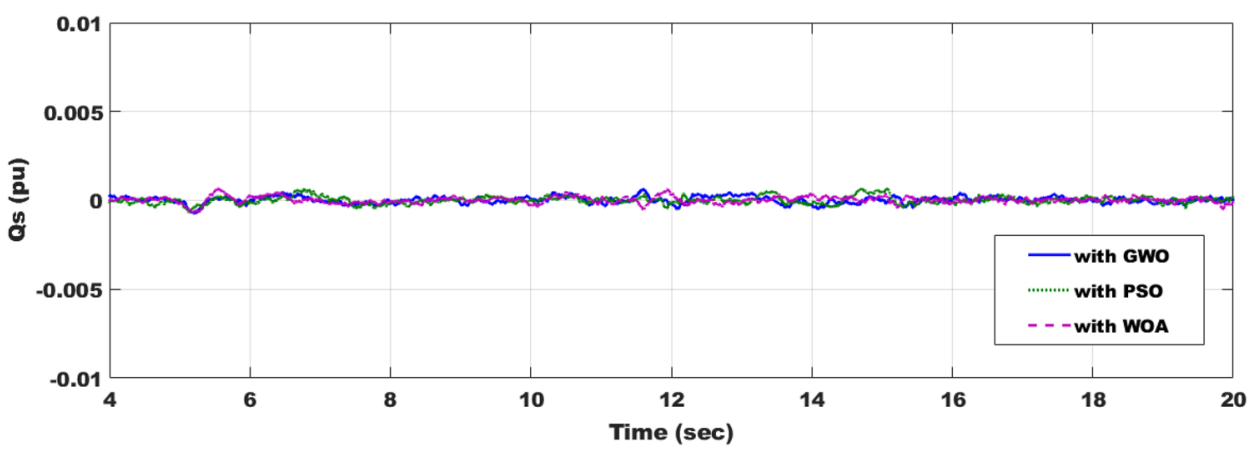

(b)

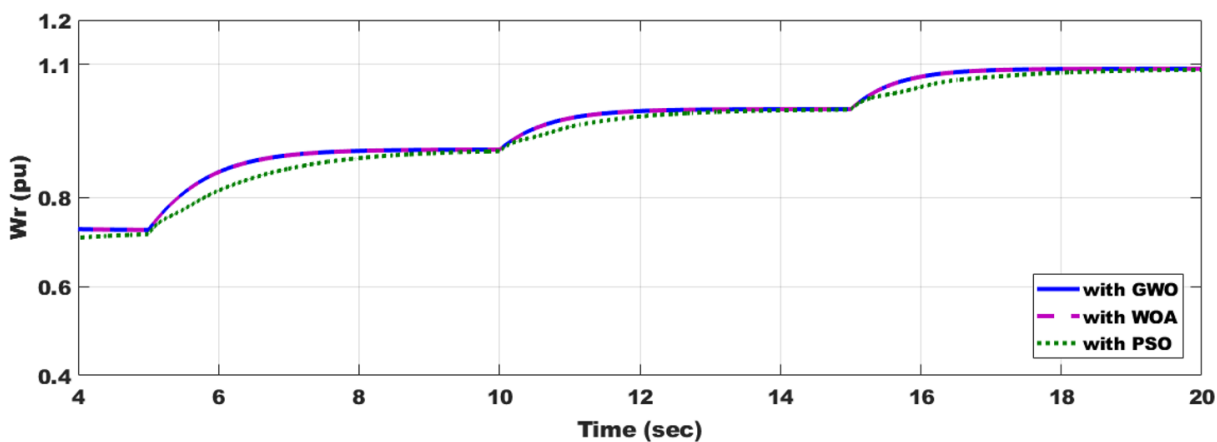

(c)

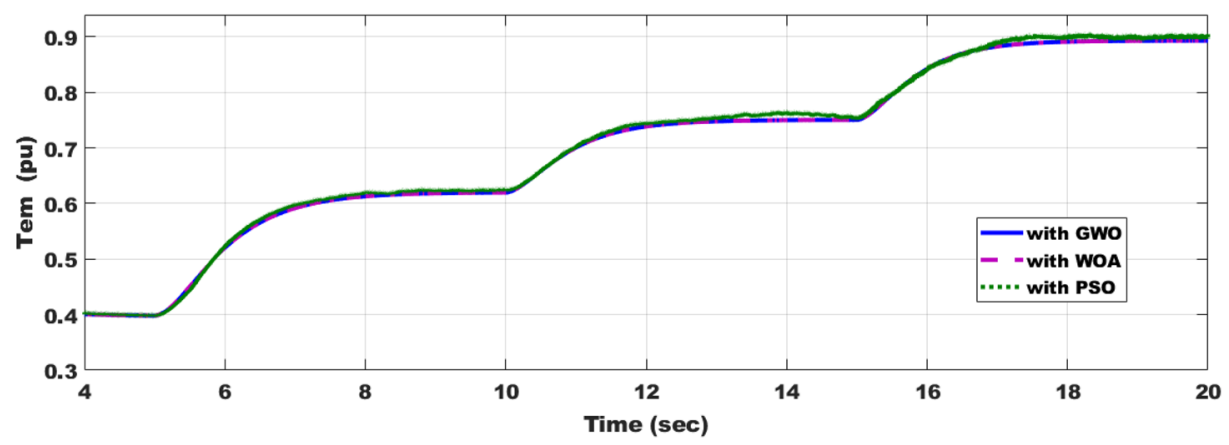

(d) 
Fig. 13 (continued)

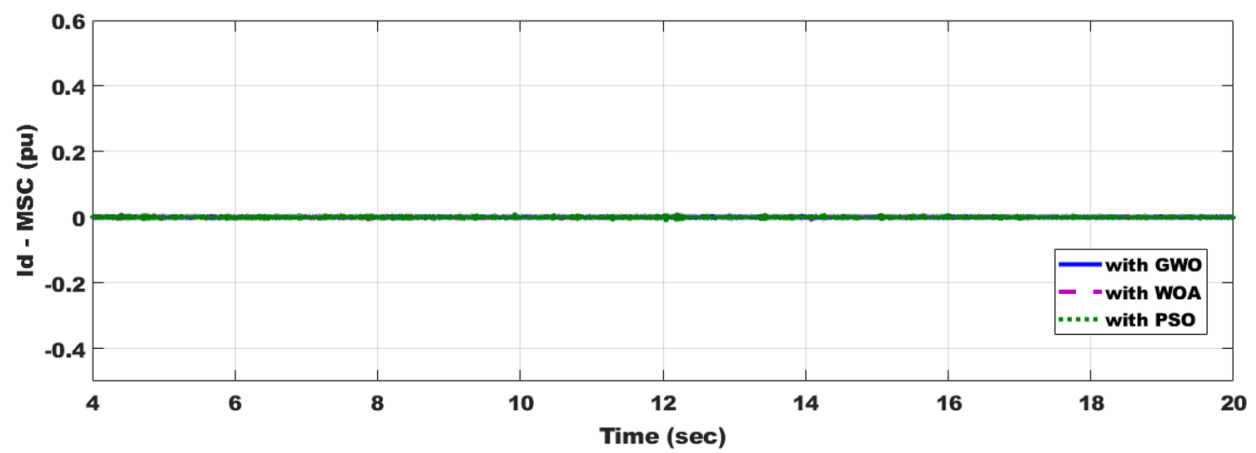

(e)

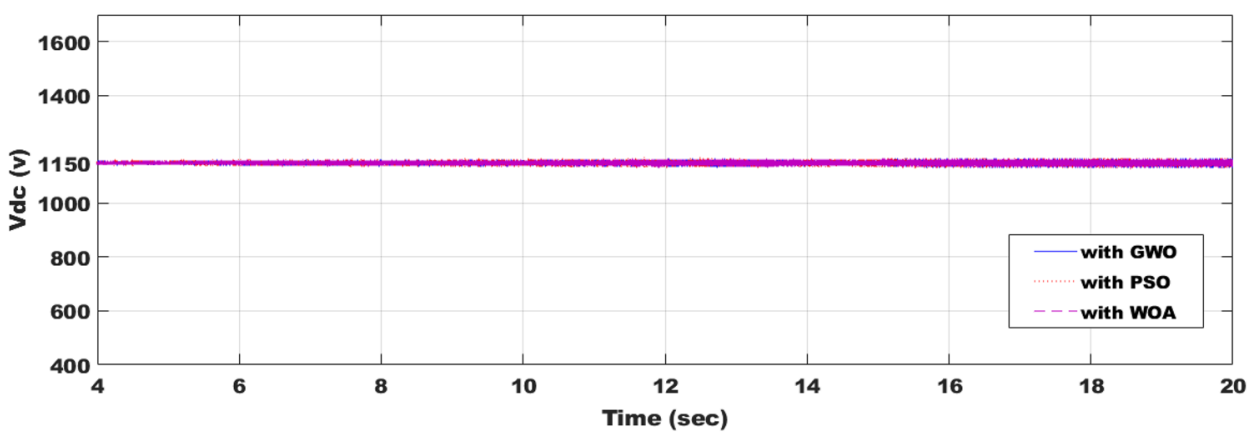

(f)

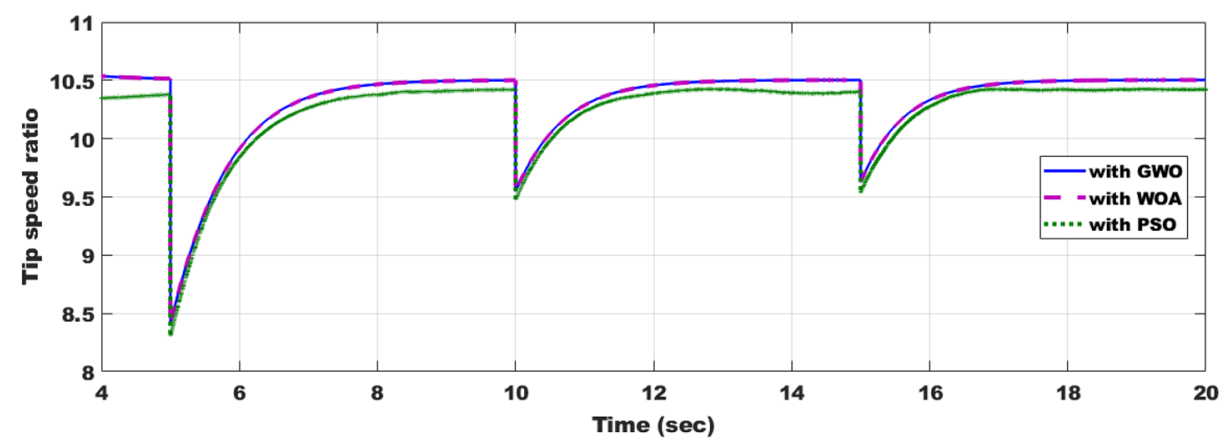

(g)

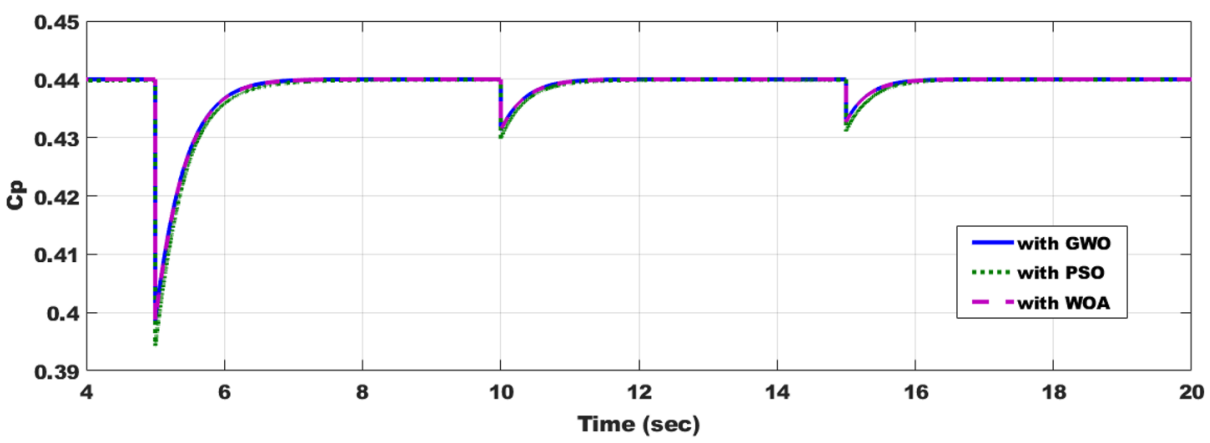

(h)

Case 3 FRT capability for wind power PMSG

For simulated system, an $85 \%$ voltage drop on the grid occurs at $t=3 \mathrm{~s}$ and cleared at $t=3.15 \mathrm{~s}$ and wind speed is at it is rated $12 \mathrm{~m} \mathrm{~s}^{-1}$. Due to the voltage dip on the grid, threephase current, electrical angular speed and dc link voltage rise, but electromagnetic torque decreases. On the other hand, oscillations occur in direct and quadrature currents, 
and GWO technique includes BC success in assisting the damping oscillations in all parameters. Excessive energy that cannot be transmitted to the grid was dissipated by BC. Dc link voltage increases due to active power injected to grid mismatch. A mismatch between the mechanical power from wind turbines and real output power leads to the increase in rotor speed or due to the high inertia of the generator. Reactive power is set to be zero because of the unity power factor. The increase in reactive power during fault assists PMSG to realize FRT (Fig. 14).
Fig. 14 Simulated results. a Three-phase voltages, b threephase currents, c electromagnetic torque $\left(T_{\mathrm{e}}\right)$, d rotor speed $\left(\omega_{\mathrm{r}}\right)$, e dc link voltage $\left(V_{\mathrm{dc}}\right), \mathbf{f}$ direct current for MSC $\left(I_{\mathrm{d}}-\right.$ MSC), (g) quadrature current for MSC (I $-M S C)$, h quadrature current for GSC $\left(I_{\mathrm{q}}-\mathrm{GSC}\right)$, i direct current for GSC $\left(l_{\mathrm{d}}-\right.$ GSC), $\mathbf{j}$ injected active power to the grid $\left(P_{\mathrm{s}}\right), \mathbf{k}$ injected reactive power to the grid $\left(Q_{s}\right)$

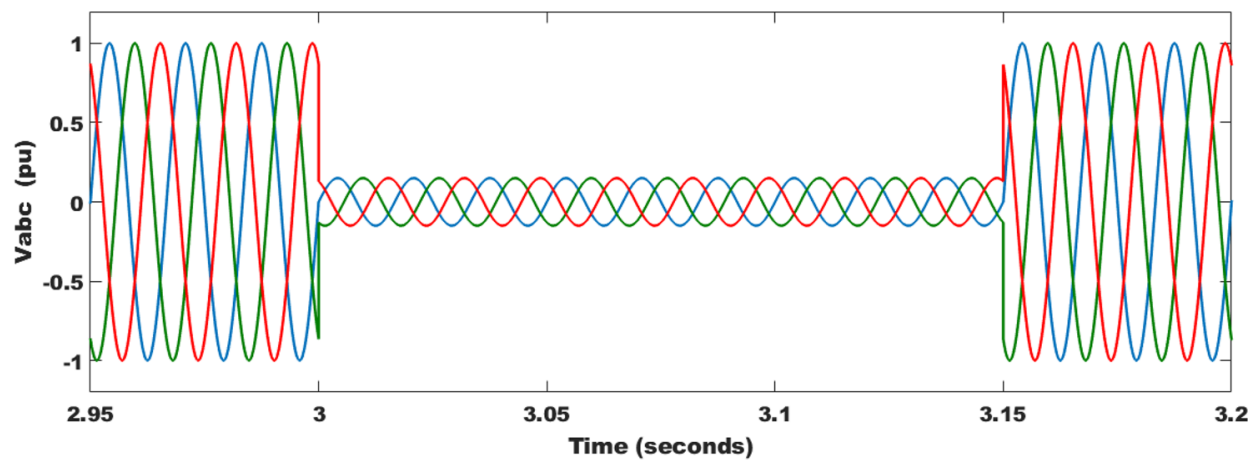

(a)

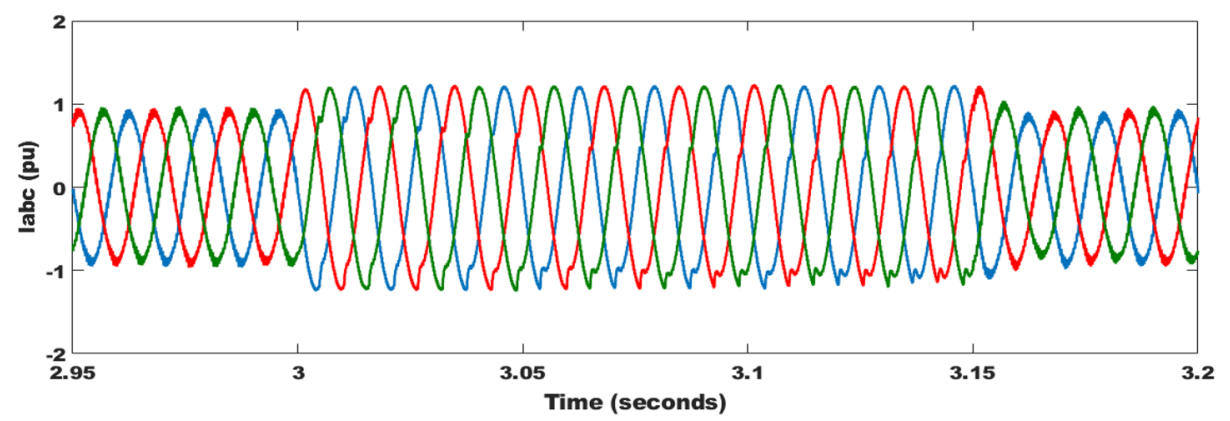

(b)

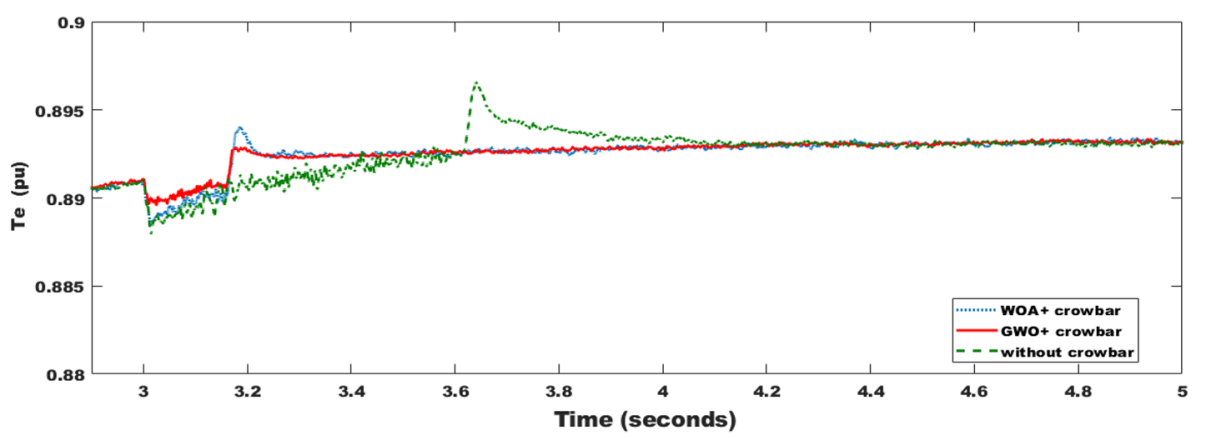

(c)

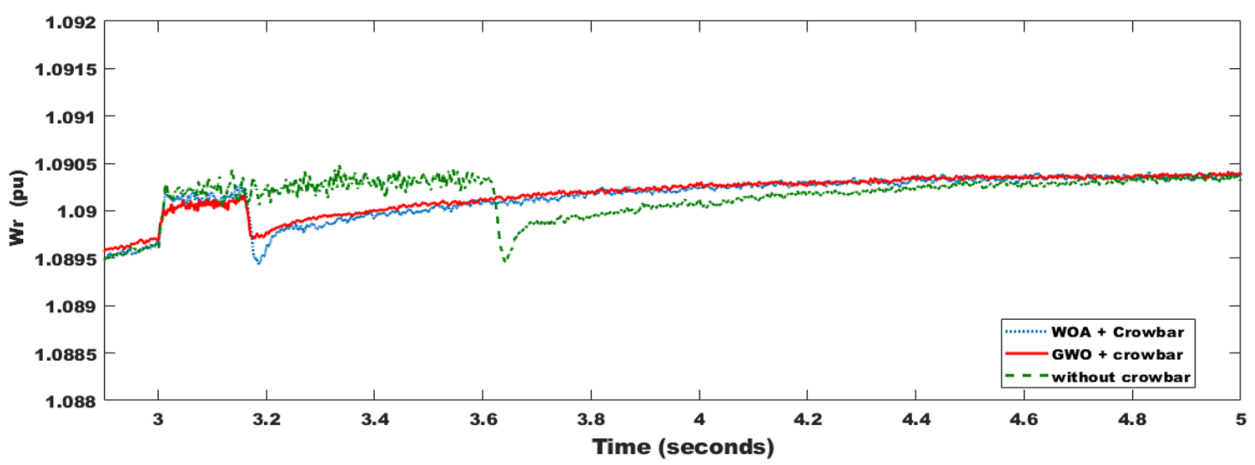

(d) 
Fig. 14 (continued)

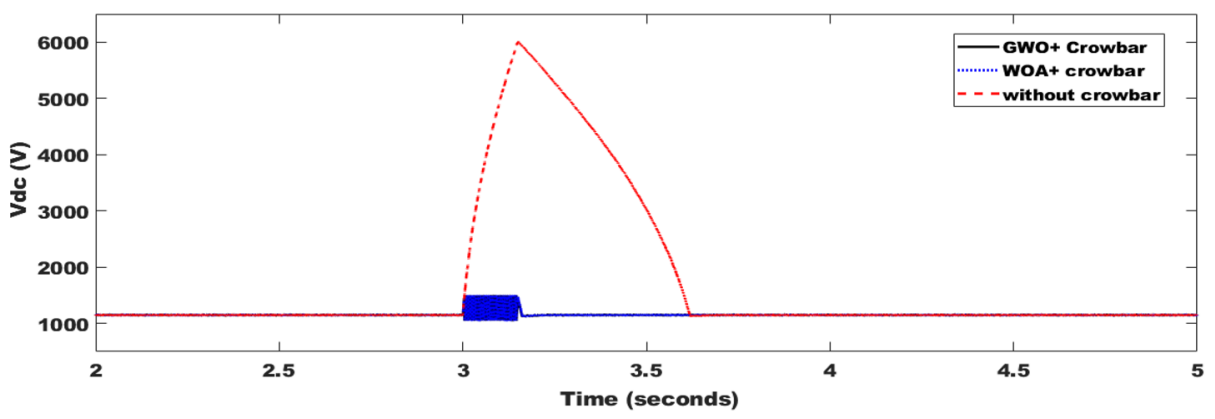

(e)

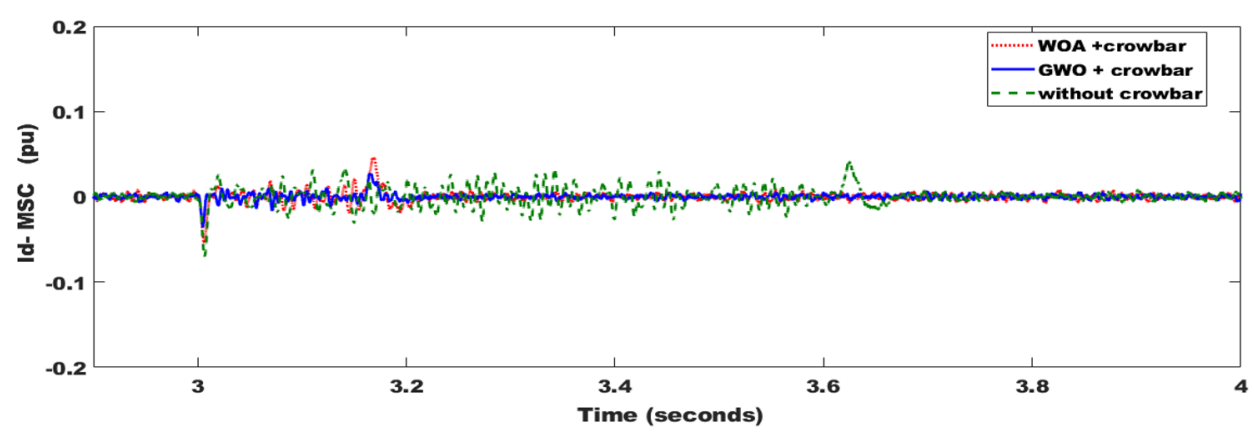

(f)

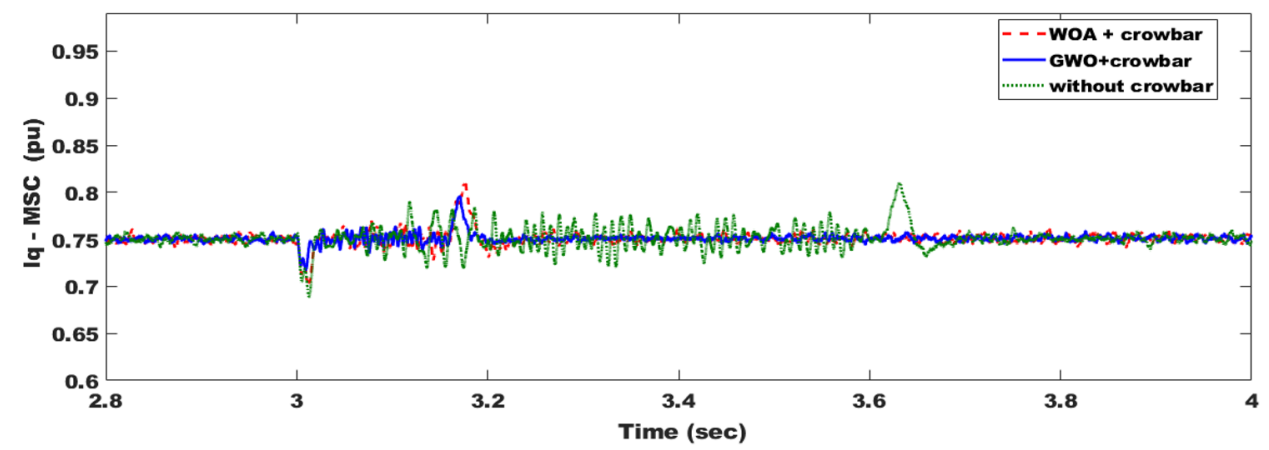

(g)

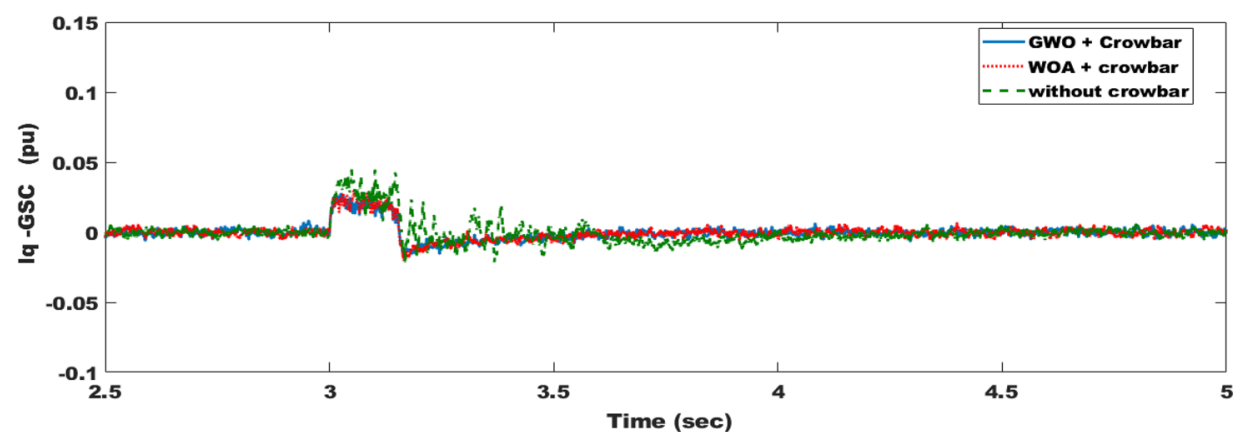

(h) 
Fig. 14 (continued)

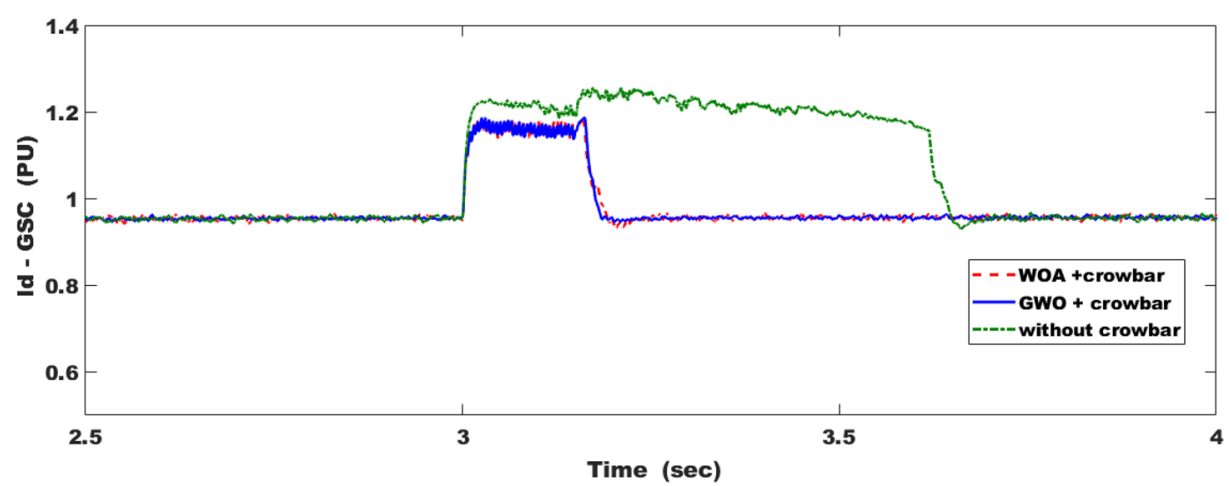

(i)

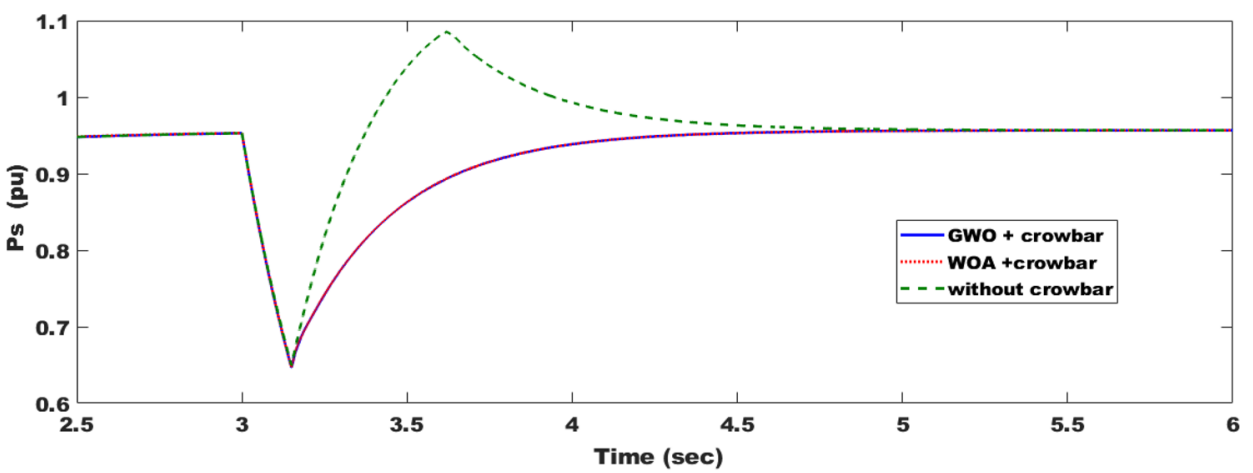

(j)

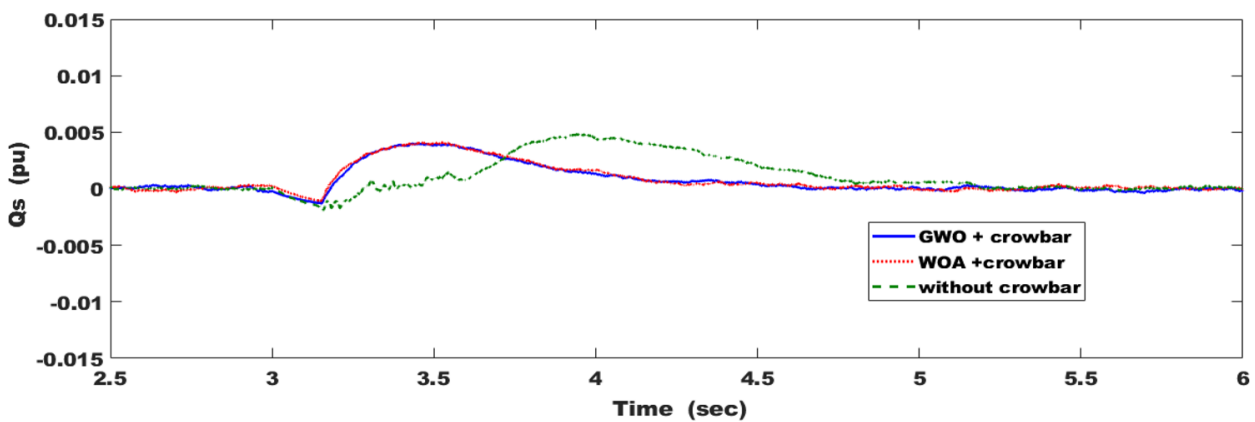

(k)

\section{Conclusion}

In this paper, different operating conditions are considered to get the optimal parameters of the PI controller. The proposed PI-based PSO provides MPPT during wind speed variation. The proposed PI-based WOA provides MPPT during wind speed variation and also introduces an improvement in FRT capability realization. The proposed PI-based GWO provides MPPT during wind speed variation and also aid in FRT capability realization. The TSR algorithm has succeeded in operating PMSG at MPPT at a given wind speed. In order to help PMSG ride through grid faults, BC was introduced into the dc connection. As dealing with the same operating conditions, GWO shows better results for PMSG than other optimization approaches. While GWO and WOA are identical in the case of variance in wind speed, the PI values for GWO are lower, meaning low cost. The PMSG including BC is checked under symmetrical fault for the realization of FRT capability with GWO and WOA techniques. The results show the superiority of GWO technique in FRT achieving compared with WOA. Finally, it can be concluded that PMSG's operation with GWO technique based on PI controller and $\mathrm{BC}$ was the most effective under all the scenarios studied.

\section{Compliance with ethical standards}

Conflict of interest The authors declare that no conflict of interest. 


\section{Appendix}

See Tables 3 and 4.

Table 3 Parameters for simulated wind-driven PMSG [10]

\begin{tabular}{ll}
\hline Parameter & Value \\
\hline Rated power & $1.5[\mathrm{MW}]$ \\
Rated stator voltage & $575[\mathrm{~V}]$ \\
Rated frequency & $60[\mathrm{~Hz}]$ \\
Dc link voltage & $1150[\mathrm{~V}]$ \\
Pole pairs & 40 \\
Generator inductance in the d frame & $0.7[\mathrm{p.u}]$ \\
Generator inductance in the q frame & $0.7[\mathrm{p} . \mathrm{u}]$ \\
Generator stator resistance & $0.01[\mathrm{p} . \mathrm{u}]$ \\
Flux of the permanent magnets & $0.9[\mathrm{p} . \mathrm{u}]$ \\
Line inductance & $0.3[\mathrm{p} . \mathrm{u}]$ \\
Line resistance & $0.003[\mathrm{p} . \mathrm{u}]$ \\
\hline
\end{tabular}

Table 4 BC resistance parameters [31]

\begin{tabular}{ll}
\hline Resistance & $1.5 \Omega$ \\
Rated power & $12 \mathrm{~kW}$ \\
Maximum temperature & $150^{\circ} \mathrm{C}$ \\
Thermal time constant & $4 \mathrm{~min}$ \\
Weight & $30 \mathrm{~kg}$ \\
Dimensions & $(750,330,150) \mathrm{mm}$ \\
\hline
\end{tabular}

\section{References}

1. Kaldellis J, Apostolou D (2017) Life cycle energy and carbon footprint of offshore wind energy. Comparison with onshore counterpart. Renew Energy 108:72-84

2. Aliyu AK, Modu B, Tan CW (2018) A review of renewable energy development in Africa: a focus in South Africa, Egypt and Nigeria. Renew Sustain Energy Rev 81:2502-2518

3. Hossain MM, Ali MH (2015) Future research directions for the wind turbine generator system. Renew Sustain Energy Rev 49:481-489

4. Xie D, Lu Y, Sun J, Gu C (2017) Small signal stability analysis for different types of PMSGs connected to the grid. Renew Energy 106:149-164

5. Tripathi S, Tiwari A, Singh D (2015) Grid-integrated permanent magnet synchronous generator based wind energy conversion systems: a technology review. Renew Sustain Energy Rev 51:1288-1305

6. Li H, Chen Z (2008) Overview of different wind generator systems and their comparisons. IET Renew Power Gener 2:123-138

7. Nahome AA, Zaimeddine R, Liu B, Undeland T (2011) Vector control of direct drive six phase permanent magnet synchronous generators. In: 2011 IEEE Trondheim, PowerTech, pp 1-7

8. Mousa HHH, Youssef A-R, Mohamed EEM (2019) Model predictive speed control of five-phase permanent magnet synchronous generator-based wind generation system via wind-speed estimation. Int Trans Electr Energy Syst 29(5):e2826

9. Yaramasu V, Dekka A, Durán MJ, Kouro S, Wu B (2017) PMSGbased wind energy conversion systems: survey on power converters and controls. IET Electr Power Appl 11(6):956-968

10. Shehata $E$ (2017) A comparative study of current control schemes for a direct-driven PMSG wind energy generation system. Electr Power Syst Res 143:197-205

11. Kumar D, Chatterjee K (2016) A review of conventional and advanced MPPT algorithms for wind energy systems. Renew Sustain Energy Rev 55:957-970

12. Athari $H$, Niroomand $M$, Ataei $M$ (2017) Review and classification of control systems in grid-tied inverters. Renew Sustain Energy Rev 72:1167-1176

13. Vijayapriya R, Raja P, Selvan MP (2017) A modified active power control scheme for enhanced operation of PMSG-based WGs. IEEE Trans Sustain Energy 9(2):630-638

14. Nasiri M, Milimonfared J, Fathi S (2015) A review of low-voltage ride-through enhancement methods for permanent magnet synchronous generator based wind turbines. Renew Sustain Energy Rev 47:399-415

15. Gencer A (2018) Analysis and control of fault ride through capability improvement PMSG based on WECS using active crowbar system during different fault conditions. Elektronika ir Elektrotechnika 24(2):63-69

16. Xu L, Lin R, Ding L, Zhang $H$, Li S, Huang $C$ (2019). A new frt method of pmsg under grid faults by using improved msc control and smes device. In: IOP conference series: materials science and engineering, vol 490, no 7. IOP Publishing, p 072032)

17. Akpeke NE, Muriithi CM, Mwaniki C (2019) Contribution of FACTS devices to the transient stability improvement of a power system integrated with a PMSG-based wind turbine. Eng Technol Appl Sci Res 9(6):4893-4900

18. Lertnuwat $C$, Leeton $U$, Oonsivilai A (2018). Optimization for wind turbine with permanent magnet synchronous generator (PMSG) using optimal control design. In: 2018 international electrical engineering congress (iEECON). IEEE, pp 1-4

19. Yang B, Yu T, Shu H, Zhang X, Qu K, Jiang L (2018) Democratic joint operations algorithm for optimal power extraction of PMSG based wind energy conversion system. Energy Convers Manag 159:312-326

20. Dabrowski M (2010) Permanent magnet motor technology: design and applications. Ed: Wydawnictwo SIGMA-NOT Sp Zoo ul Ratuszowa 11, PO Box 1004, 00-950 Warsaw, Poland

21. Mohamed SA (2019) Multi-input rectifier stage for a system of hybrid PV/wind driven PMSG. SN Appl Sci 1(12):1578

22. Rahimi M (2017) Modeling, control and stability analysis of grid connected PMSG based wind turbine assisted with diode rectifier and boost converter. Int J Electr Power Energy Syst 93:84-96

23. Mirjalili S, Lewis A (2016) The whale optimization algorithm. Adv Eng Softw 95:51-67

24. Uddin MN, Amin IK (2019) Adaptive step size based hill-climb search algorithm for MPPT control of DFIG-WECS with reduced power fluctuation and improved tracking performance. Electr Power Compon Syst 49:2203-2214

25. Barros L, Barros C (2017) An internal model control for enhanced grid-connection of direct-driven PMSG-based wind generators. Electr Power Syst Res 151:440-450

26. Abdel-Moamen MA, Shaaban SA, Jurado F (2017). Francespain hvdc transmission system with hybrid modular multilevel converter and alternate-arm converter. In: 2017 innovations in power and advanced computing technologies (i-PACT), IEEE, pp 1-6 
27. Qais MH, Hasanien HM, Alghuwainem S (2018) Augmented grey wolf optimizer for grid-connected PMSG-based wind energy conversion systems. Appl Soft Comput 69:504-515

28. Hebala A, Hebala O, Ghoneim WA, Ashour HA (2017). Multiobjective particle swarm optimization of wind turbine directly connected PMSG. In: 2017 nineteenth international middle east power systems conference (MEPCON). IEEE, pp 1075-1080

29. Qais MH, Hasanien HM, Alghuwainem S, Elgendy MA (2019). Output power smoothing of grid-tied PMSG-based variable speed wind turbine using optimal controlled SMES. In: 2019 54th international universities power engineering conference (UPEC). IEEE, pp 1-6
30. Qais MH, Hasanien HM, Alghuwainem S (2020) Whale optimization algorithm-based Sugeno fuzzy logic controller for fault ridethrough improvement of grid-connected variable speed wind generators. Eng Appl Artif Intell 87:103328

31. El Moursi MS, Zeineldin HH (2014) A parallel capacitor control strategy for enhanced FRT capability of DFIG. IEEE Trans Sustain Energy 6(2):303-312

Publisher's Note Springer Nature remains neutral with regard to jurisdictional claims in published maps and institutional affiliations. 